\title{
Quantification of Multi-class Cyanopeptides in Swiss Lakes with Automated Extraction, Enrichment and Analysis by Online-SPE HPLC-HRMS/MS
}

\author{
Martin R. Jones ${ }^{\mathrm{a}}$ and Elisabeth M. L. Janssen ${ }^{\star b}$
}

\begin{abstract}
The frequency and intensity of cyanobacterial blooms continue to increase in freshwater systems across the globe. Cyanobacteria can release toxins and several bioactive secondary metabolites and analytical methods are needed to effectively assess their concentrations in surface waters. Since blooms can evolve rapidly in parts of a lake, high resolution of spatial and temporal sampling increases the complexity of monitoring efforts. Here, we present the validation of an automated, online-solid phase extraction (SPE) high performance liquid chromatography (HPLC)-high resolution tandem mass spectrometry (HRMS/MS) method. This online-SPE HPLC-HRMS/MS method enables quantitative monitoring of surface waters for 17 cyanobacterial peptides (cyanopeptides), spanning 5 distinct cyanopeptide classes, including: microcystins, anabaenopeptins, nodularins, cyclamides and cyanopeptolins. The method can quantify these cyanopeptides in the low ng/L-range with high accuracy $(85-116 \%)$ and low relative matrix effects $(<25 \%)$. We demonstrated its application to Swiss lake waters (Zürichsee, Hallwilersee, Greifensee), which also highlighted the value of adding cyanopeptides beyond common microcystins when monitoring surface waters for cyanobacteria.
\end{abstract}

Keywords: Analytical method - Cyanobacteria $\cdot$ Cyanotoxins · Mass spectrometry $\cdot$ Natural toxins

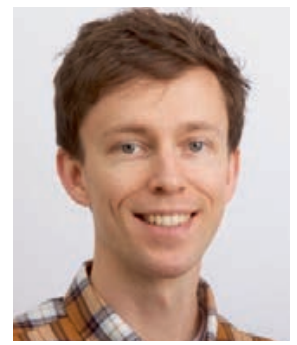

Martin Jones received his $\mathrm{PhD}$ in 2017 from the University of Birmingham, UK, where his research focused on developing an analytical and bioinformatics workflow to support the deep annotation of metabolomes. His post-doctoral research in Environmental Chemistry at the Swiss Federal Institute of Aquatic Science and Technology (Eawag) focused on developing analytical techniques and data analysis workflows to support the detection and annotation of emerging cyanobacterial metabolites. He is now working as a post-doctoral researcher at the University of Birmingham, helping to establish sample preparation and computational capabilities for delivery of Precision Toxicology.

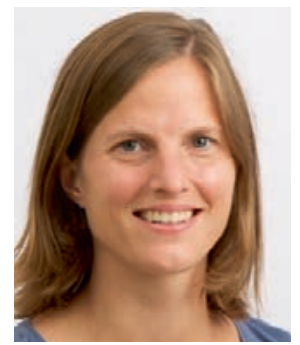

Elisabeth Janssen received her $\mathrm{PhD}$ in 2010 from Stanford University in Environmental Engineering and Sciences before conducting post-doctoral research at the Natural History Museum in London (UK, 2011) and in Environmental Chemistry at ETH Zurich (2012-2015) where she continued as a senior researcher in photochemistry. Since 2016, she is a research group leader in the Environmental Chemistry department at the Swiss Federal Institute of Aquatic Science and Technology (Eawag) focusing on the environmental chemistry of micropollutants and biomolecules including occurrence and fate processes of cyanobacterial toxins.

\section{Introduction}

Cyanobacteria can produce toxins and compromise water quality, especially during dense bloom events. ${ }^{[1,2]}$ With increasing nutrient input and changes in thermal and hydrological conditions, cyanobacterial blooms are becoming more frequent and intense, posing risks to human and animal health, and disrupting activities of socio-economic importance associated with affected water bodies. ${ }^{[3]}$ Blooms frequently occur in lakes ${ }^{[4]}$ and drinking water reservoirs across the globe. ${ }^{[5]}$ Swiss waters are also affected by seasonal increases in cyanobacterial loads, including the peri-alpine lakes, lake Zürichsee, lake Greifensee and lake Hallwilersee. ${ }^{[4,6]}$ Stakeholders concerned with the use and management of water resources are prompted to develop strategic action plans to react to bloom events. These strategies include monitoring of cyanobacterial cell counts and toxin concentrations in the water. ${ }^{[7]}$ Direct quantification of toxins is essential because the production dynamics of toxins is currently not predicted adequately based solely on the abundance of cyanobacteria cells. Microcystin-LR, cylindrospermopsin, anatoxin-a, and saxitoxin are cyanobacterial metabolites recognized as toxins and included in the water quality guidelines by the World Health Organization. ${ }^{[7]}$ Cyanobacteria co-produce several secondary metabolites along with these known toxins. Indeed, to date, more than 2000 cyanobacterial metabolites have been identified, ranging in mass from 100 to $2500 \mathrm{Da}^{\left[{ }^{[8]}\right.}$ Approximately $65 \%$ of cyanobacterial metabolites are categorized as peptide-based organic molecules, called cyanopeptides. ${ }^{[8,9]}$ Cyanopeptides can be further classified based on similarities of their structural motifs for example as microcystins, nodularins, cyanopeptolins, anabaenopeptins and cyclamides (Fig. 1). Cyanopeptides can fulfill diverse roles in defense against 
other organisms (antibiotics, herbicides, fungicides, etc.), in facilitating symbiosis as metal transporting agents, and as photoprotectants, antioxidants, differentiation effectors or allelochemicals. ${ }^{[10]}$ Unique and characteristic substructures and alterations of monomers define different variants within each class. One cyanopeptide can be produced by different cyanobacterial taxa ${ }^{[2 b, 11]}$ and one cyanobacterial species can harbour the biosynthesis pathways for cyanopeptides of different classes. ${ }^{[11 f, 12]}$ Consequently, these cyanopeptides occur just as frequently in surface waters across the globe as toxic microcystins but their analytical identification and quantification is still challenging. ${ }^{[4 a c, 5 a b, 13]}$ There are two main advantages to include other metabolites in monitoring studies beyond Microcystin-LR (MC-LR), cylindrospermopsin, anatoxin-a, and saxitoxin. First, other bioactive metabolites may be easier to detect if they occur in higher abundance or their analytical detection limits are lower compared to the toxins included in the WHO guidelines. Second, other bioactive metabolites can contribute to toxic effects posed by cyanobacteria that cannot be explained by the presence of known toxins alone. ${ }^{[4,14,15]}$
While instrumental detection limits in the low $\mathrm{ng} / \mathrm{L}$ range can be achieved by LC-MS/MS, enrichment and matrix removal from natural samples is often required, for example using solid-phase extraction (SPE). In the past decade automated loading and elution of a SPE cartridge directly coupled to the LC-MS/MS was accomplished for the simultaneous analysis of a wide range of micropollutants using column switching techniques and a tri-directional autosampler system. ${ }^{[17]}$ These online-SPE-LC-MS/MS systems achieve higher reproducibility and sample throughput, decrease the manual labour time by more than five-fold, and reduced costs of SPE cartridges by $75 \%$ by realizing the analysis of up to 500 samples with one extraction cartridge. Recent studies demonstrate that online-SPE can also be successfully applied in the analysis of microcystins and other cyanopeptides. ${ }^{[18]}$

In this study, we evaluated the performance of an online-SPE-HPLC-HRMS/MS method as a tool for monitoring multi-class cyanopeptides in lake waters, including 10 microcystins, 3 anabaenopeptins, 2 cyanopeptolins, aerucyclamide A and nodularin-R. For each compound, the validation procedure included
Microcystins

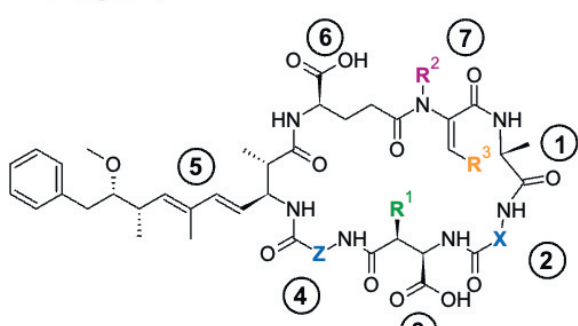

(3)
Nodularin-R

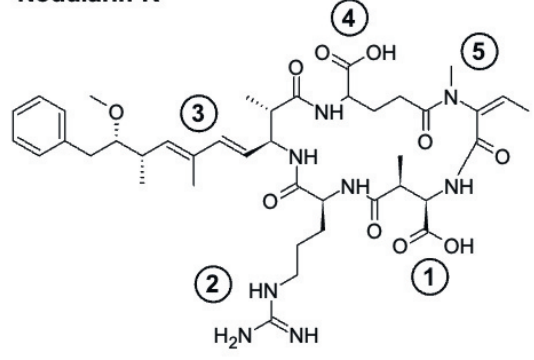

Aerucyclamide A

Cyanopeptolins

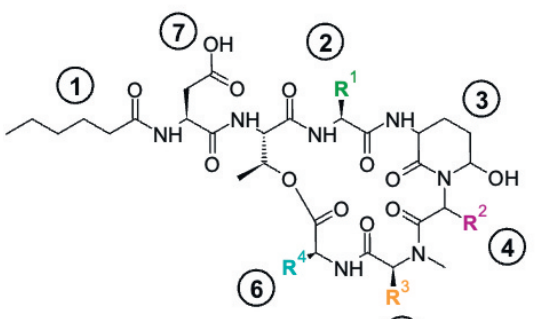

(5)

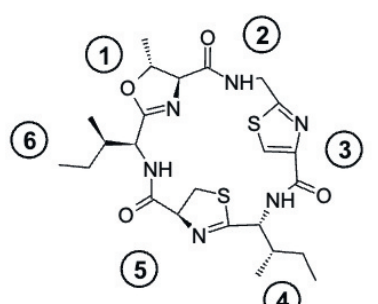

(4)
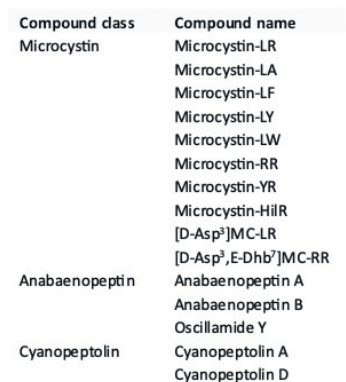

Anabaenopeptins

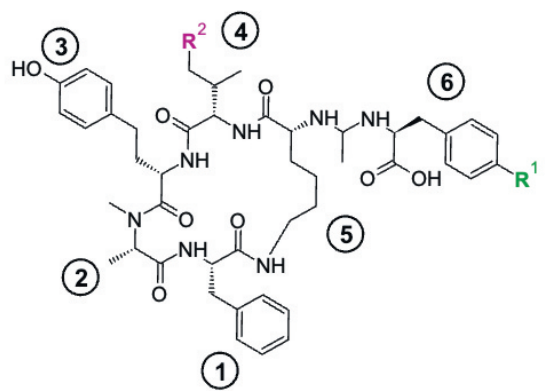

Fig. 1. Structural overview of the five cyanopeptide classes included in the validation tests, showing one representative compound per class: microcystin-LR; nodularin-R, oscillamide $Y$, cyanopeptolin A, and aerucyclamide A. Numbers indicate loci of the 'building blocks' for each compound class, with letters ' $X$ ' and ' $Z$ ' corresponding to the most common loci for chemical structural variability among microcystins. The inset table indicates the chemical structures found at each building block location in targeted cyanopeptides belonging to classes microcystin, anabaenopeptin and cyanopeptolin. All structures drawn using ChemSketch Freeware version 2021.1.1.

The most reliable and sensitive method for quantifying individual cyanopeptides is liquid chromatography coupled with tandem mass spectrometry (LC-MS/MS). Even though more than 1300 cyanopeptides including 279 microcystins have been structurally identified to date, ${ }^{[8]}$ only a few reference standards are commercially available and commonly used. These include nodularin and various microcystins variants: MC-LR, MC-LF, MC-LA, MC-LY, MC-LW, MC-RR and MC-YR. In recent years, several bioreagents have also been offered commercially with slightly lower purity for approximately 10 additional microcystins and a few dozen other cyanopeptides, expanding opportunities for targeted analysis. Studies quantifying absolute concentrations of cyanopeptides beyond microcystins in lake samples, using in-house gravimetric reference standards or commercially available bioreagents, have shown that microcystins are not always the dominate class of cyanopeptides reaching drinking water treatment plants. ${ }^{[9 d, 16]}$ determination of methodological limits of detection and quantification (mLOD and $\mathrm{mLOQ}$ ), accuracy, intra- and inter-day precision, matrix effects (in lake water), recovery and carryover, based on calibration curves ranging between $\approx 1-1000 \mathrm{ng} / \mathrm{L}$. We then applied this method to quantify cyanopeptides directly in water samples collected from three Swiss lakes, with the results emphasizing the benefits of including additional cyanopeptides beyond known toxins for strategic monitoring and risk assessment of cyanobacteria.

\section{Experimental Section}

\subsection{Materials}

Microcystin-LA (MC-LA), microcystin-LF (MC-LF), microcystin-LR (MC-LR), microcystin-LW (MC-LW), microcystin-LY (MC-LY), microcystin-RR (MC-RR), microcystin-YR (MCYR), microcystin-HilR (MC-HilR), [D-Asp $\left.{ }^{3}\right]$ microcystin-LR 
([D-Asp $\left.\left.{ }^{3}\right] \mathrm{MC}-\mathrm{LR}\right)$ and nodularin-R (Nod) standards were purchased from Enzo Life Sciences ( $\geq 95 \%$ ( $>95 \%$ purity by HPLC). Cyanopeptolin A, cyanopeptolin D, oscillamide Y, anabaenopeptin A, anabaenopeptin B were purchased from CyanoBioTech $\mathrm{GmbH}$ (all $>90 \%$ purity by HPLC) as well as $\left[\mathrm{D}-\mathrm{Asp}^{3},(E)-\mathrm{Dhb}^{7}\right]$ microcystin-RR ( $>95 \%$ purity by HPLC). Aerucyclamide A was kindly provided as a purified bioreagent in dimethylsulfoxide by Prof. Karl Gademann (University Zurich, Switzerland). Solvents and mobile phase additives were purchased from the following suppliers: methanol and acetonitrile (Optima LC-MS grade) from Fisher Scientific; formic acid (98-100\%, analysis grade) and ethanol (absolute; glass bottle) from Merck. A Nanopure water purification system was used to generate water $\left(18.2 \mathrm{M} \Omega \mathrm{cm}^{-1}\right)$ used in the preparation of solutions and for HPLC-HRMS analyses. Individual cyanopeptide stock solutions were prepared around 50 $\mathrm{mg} / \mathrm{L}$ in ethanol from 17 cyanopeptide standards or bioreagents (exact concentrations vary slightly), as depicted in Fig. 1 and Table 1, below. Stock solutions were combined to generate a pool of the 17 cyanopeptides and diluted in either nanopure water or filtered lake water (lake Greifensee, $28^{\text {th }}$ May 2020) to generate calibrants with concentrations ranging between 0.4 and $1000 \mathrm{ng} / \mathrm{L}$. Lake matrix calibrants were stored at $-20{ }^{\circ} \mathrm{C}$ after preparation to account for the freeze-thaw cycle applied to lake water samples. Nanopure water-based calibrant solutions were prepared fresh immediately prior to analysis and stored at $4{ }^{\circ} \mathrm{C}$ until loaded on to the autosampler. Lake water samples were collected from three Swiss lakes between June and November 2019 using 5 L Niskin bottles, with the depth of collection corresponding to the chlorophyll-a maximum for lakes Zürichsee and Hallwilersee, and at $3 \mathrm{~m}$ for lake Greifensee. The contents were passed through a coarse gauze mesh ( $90 \mu \mathrm{m}$ nylon) into $2 \mathrm{~L}$ clear-glass Schott bottles for transport to the laboratory inside a cooler box (dark, ambient temperature). Within 2 hours of sampling, native $\mathrm{pH}$ was recorded and adjusted to $\mathrm{pH} 9$ using $1 \mathrm{M} \mathrm{NaOH}$ (aq.) and $1 \mathrm{M}$ $\mathrm{HCl}$ (aq.). Thereafter, samples were individually filtered under vacuum (GF/F, $0.7 \mu \mathrm{m}, 47 \mathrm{~mm}$; Whatman) using a glass, bottle-top filtration device. From each resulting $1 \mathrm{~L}$ filtrate, a $40 \mathrm{~mL}$ aliquot was stored in a glass vial at $-20{ }^{\circ} \mathrm{C}$ until analysis. Prior to online-SPE HPLC-HRMS/MS analyses, thawed lake filtrates and lake matrix-based calibrant solutions were filtered through $\mathrm{GF} / \mathrm{F}$ syringe filters $(0.7 \mu \mathrm{m}$, polypropylene syringes $)$ into glass autosampler vials and kept at $4{ }^{\circ} \mathrm{C}$ in the dark until loaded onto the autosampler on the day of analysis.

\subsection{Online-SPE and HPLC Conditions}

Online-SPE cartridges were prepared by dry-packing $20 \pm 1 \mathrm{mg}$ of Oasis HLB sorbent (15 $\mu \mathrm{m}$, Waters) into stainless steel cartridges $(20 \times 2.1 \mathrm{~mm}$, BGB Analytik AG, Germany) fitted with two stainless steel frits $(0.3 \mu \mathrm{m}$, VDS optilab) and a PTFE O-ring (M6, VDS Optilab).

All online-SPE-HPLC-HRMS/MS analyses were performed using a PAL RTC autosampler coupled to an Ultimate3000 modular UHPLC system. The PAL RTC autosampler was fitted with a $10 \mathrm{~mL}$ stainless steel sample loop, a 60-position sample tray, three six-port two-position valves and an online-SPE cartridge (at room temperature). The Ultimate 3000 comprised three distinct pump modules, referred to as 'gradient pump 1' (GP1), 'gradient pump 2' (GP2) and 'loading pump' (LP), as well as a column oven and an in-line degasser. Mobile phases A and B consisted of $0.1 \% \mathrm{v} / \mathrm{v}$ formic acid in nanopure water and methanol, respectively, and were loaded onto GP1 and GP2. Mobile phase C and $\mathrm{D}$ consisted of $100 \%$ nanopure water and $0.5 \% \mathrm{v} / \mathrm{v}$ formic acid in acetonitrile, respectively, and were loaded onto LP. Analytes were separated over a Kinetex $\mathrm{C}_{18}$ HPLC column $(2.1$ x 100 mm,

\begin{tabular}{|c|c|c|c|c|}
\hline cyanopeptide & $\begin{array}{l}\text { molecular } \\
\text { formula }\end{array}$ & $\begin{array}{l}\text { Monoisotopic mass } \\
\text { (Da; rounded to } 5 \text { d.p.) }\end{array}$ & \multicolumn{2}{|c|}{$\begin{array}{c}\text { dominant precursor ion } \\
\text { and } m / z \text { value }\end{array}$} \\
\hline Aerucyclamide A & $\mathrm{C}_{24} \mathrm{H}_{34} \mathrm{~N}_{6} \mathrm{O}_{4} \mathrm{~S}_{2}$ & 534.20830 & {$[\mathrm{M}+\mathrm{H}]^{+}$} & 535.21557 \\
\hline Anabaenopeptin A & $\mathrm{C}_{44} \mathrm{H}_{57} \mathrm{~N}_{7} \mathrm{O}_{10}$ & 843.41669 & {$[\mathrm{M}+\mathrm{H}]^{+}$} & 844.42397 \\
\hline Anabaenopeptin B & $\mathrm{C}_{41} \mathrm{H}_{60} \mathrm{~N}_{10} \mathrm{O}_{9}$ & 836.45447 & {$[\mathrm{M}+\mathrm{H}]^{+}$} & 837.46175 \\
\hline Oscillamide Y & $\mathrm{C}_{45} \mathrm{H}_{59} \mathrm{~N}_{7} \mathrm{O}_{10}$ & 857.43234 & {$[\mathrm{M}+\mathrm{H}]^{+}$} & 858.43962 \\
\hline Cyanopeptolin A & $\mathrm{C}_{46} \mathrm{H}_{72} \mathrm{~N}_{10} \mathrm{O}_{12}$ & 956.53312 & {$[\mathrm{M}+\mathrm{H}]^{+}$} & 957.54039 \\
\hline Cyanopeptolin D & $\mathrm{C}_{48} \mathrm{H}_{76} \mathrm{~N}_{8} \mathrm{O}_{12}$ & 956.55827 & {$[\mathrm{M}+\mathrm{H}]^{+}$} & 957.56555 \\
\hline MC-LR & $\mathrm{C}_{49} \mathrm{H}_{74} \mathrm{~N}_{10} \mathrm{O}_{12}$ & 994.54877 & {$[\mathrm{M}+\mathrm{H}]^{+}$} & 995.55604 \\
\hline MC-HilR & $\mathrm{C}_{50} \mathrm{H}_{76} \mathrm{~N}_{10} \mathrm{O}_{12}$ & 1008.56442 & {$[\mathrm{M}+\mathrm{H}]^{+}$} & 1009.57169 \\
\hline MC-LA & $\mathrm{C}_{46} \mathrm{H}_{67} \mathrm{~N}_{7} \mathrm{O}_{12}$ & 909.48477 & {$[\mathrm{M}+\mathrm{H}]^{+}$} & 910.49205 \\
\hline MC-LF & $\mathrm{C}_{52} \mathrm{H}_{71} \mathrm{~N}_{7} \mathrm{O}_{12}$ & 985.51607 & {$[\mathrm{M}+\mathrm{H}]^{+}$} & 986.52335 \\
\hline MC-LW & $\mathrm{C}_{54} \mathrm{H}_{72} \mathrm{~N}_{8} \mathrm{O}_{12}$ & 1024.52697 & {$[\mathrm{M}+\mathrm{H}]^{+}$} & 1025.53425 \\
\hline MC-LY & $\mathrm{C}_{52} \mathrm{H}_{71} \mathrm{~N}_{7} \mathrm{O}_{13}$ & 1001.51099 & {$[\mathrm{M}+\mathrm{H}]^{+}$} & 1002.51826 \\
\hline MC-RR & $\mathrm{C}_{49} \mathrm{H}_{75} \mathrm{~N}_{13} \mathrm{O}_{12}$ & 1037.56581 & {$[\mathrm{M}+2 \mathrm{H}]^{2+}$} & 519.79018 \\
\hline MC-YR & $\mathrm{C}_{52} \mathrm{H}_{72} \mathrm{~N}_{10} \mathrm{O}_{13}$ & 1044.52803 & {$[\mathrm{M}+\mathrm{H}]^{+}$} & 1045.53531 \\
\hline $\begin{array}{l}{\left[\mathrm{D}-\mathrm{Asp}^{3},(E)-\mathrm{Dhb}^{7}\right]} \\
\text { MC-RR }\end{array}$ & $\mathrm{C}_{48} \mathrm{H}_{73} \mathrm{~N}_{13} \mathrm{O}_{12}$ & 1023.55016 & {$[\mathrm{M}+2 \mathrm{H}]^{2+}$} & 512.78236 \\
\hline$\left[\mathrm{D}-\mathrm{Asp}^{3}\right] \mathrm{MC}-\mathrm{LR}$ & $\mathrm{C}_{48} \mathrm{H}_{72} \mathrm{~N}_{10} \mathrm{O}_{12}$ & 980.53312 & {$[\mathrm{M}+\mathrm{H}]^{+}$} & 981.54039 \\
\hline Nodularin-R & $\mathrm{C}_{41} \mathrm{H}_{60} \mathrm{~N}_{8} \mathrm{O}_{10}$ & 824.44324 & {$[\mathrm{M}+\mathrm{H}]^{+}$} & 825.45052 \\
\hline
\end{tabular}

Table 1. Cyanopeptides included in the validation study with their molecular formula, monoisotopic mass, and dominant precursor ion form with associated massto-charge $(\mathrm{m} / \mathrm{z})$ ratio. 
$2.6 \mu \mathrm{m}$; Phenomenex) maintained at $40{ }^{\circ} \mathrm{C}$, using a binary linear gradient of mobile phases $\mathrm{A}$ and $\mathrm{B}$ supplied at $0.255 \mathrm{~mL} / \mathrm{min}$, as follows: $20.04 / 28.63 / 50.04 / 70.02 / 100 / 100 / 20.04 / 20.04 \%$ B at 0/12/16/32/32.1/37/37.1/42.1 min.

As depicted in Fig. 2, the online-SPE-HPLC-HRMS/MS method comprised three distinct stages, namely: (a) sample loading; (b) enrichment; and (c) elution and loop washing, as previously described in the context of micropollutant screening.[17] To increase the efficiency of the online-SPE-HPLC-HRMS/MS analysis procedure, the stages are configured such that stage (c) is followed by stage (a) and, finally, by stage (b). Hence, during an analysis sequence, the sample loaded onto the online-SPE cartridge during stage (b) of injection ' $i$ ', is analysed during stage (c) of the following analysis, i.e. injection ' $i$ ' +1 .

Sample elution and loop washing (0-13 mins.): Analytes retained on the online-SPE cartridge (during the "sampling loading' stage of the previous injection) were back-flushed from the cartridge by GP1 toward the head of the analytical LC column, at a flow rate of $0.073 \mathrm{~mL} / \mathrm{min}$. Here, a binary gradient of mobile phases A and B was applied over the SPE cartridge, increasing from 70 to $100 \%$ B between 0 and 12 min and then held at $100 \%$ B until 13 min. Meanwhile, mobile phase A was continually supmin, and mixed prior to the analytical column with the SPE eluent stream generated by GP1. The resulting flow over the analytical column was $0.255 \mu \mathrm{L} / \mathrm{min}$ and the volume percentage of mobile phase B arriving at the HPLC column was always $<30 \%$ v/v to refocus the analytes head of the analytical column. While analytes were eluted from the SPE cartridge towards the HPLC column, LP was used to flush the sample loop with $100 \%$ mobile phase $\mathrm{D}$ at $1.7 \mathrm{~mL} / \mathrm{min}$ between 0 and $6 \mathrm{~min}(4.2 \mathrm{~mL}$ total $)$, followed by $100 \%$ mobile phase $\mathrm{C}$ at $1.5 \mathrm{~mL} / \mathrm{min}$ between 6 and $13 \mathrm{~min}$ (10.5mL total). Autosampler valve 3 was used to split loop effluent into organic and aqueous waste receptacles.

Sample loading and analysis (13-21 min.): $6.2 \mathrm{~mL}$ of sample was loaded into the sample loop using the PAL dilutor tool. The PAL dilutor tool was flushed with $20 \mathrm{~mL}$ of methanol, and then with $20 \mathrm{~mL}$ of 9:1 v/v nanopure water:methanol, between injections. During this stage, the online-SPE cartridge was washed with a binary linear gradient of mobile phases $\mathrm{C}$ and $\mathrm{D}$, supplied by LP at $1.7 \mathrm{~mL} / \mathrm{min}$, which increased from 0 to $100 \%$ $\mathrm{D}$ between 13.1 and 15 mins and then returned to $0 \% \mathrm{D}$ by 17 min. The flow rate was thereafter dropped to $0.5 \mathrm{~mL} / \mathrm{min}$ until 21 min during re-equilibration of the SPE cartridge (total of 2 plied between 0 and $13 \mathrm{~min}$ by GP2, at a flow rate of $0.182 \mathrm{~mL} /$

$\mathrm{mL}$ ). The combined flows of GP1 and GP2, meanwhile, supplied the user-defined HPLC elution gradient over the analytical LC column.

Sample enrichment (21-42 $\mathrm{min})$ : LP pumps nanopure water at $0.55 \mathrm{~mL} / \mathrm{min}$ through the sample loop towards the equilibrated SPE cartridge to enrich analytes (21.1-42 min). During this stage the LC elution gradient generated by GP1 and GP2 is completed, ending with re-equilibration of the analytical LC column in preparation for analysis of the next sample.

\subsection{HRMS/MS Conditions}

Analytes eluted from the HPLC column were introduced to a Fusion Lumos mass spectrometer via a heated electrospray ionisation source operated in positive ionisation mode with the following settings: $3.5 \mathrm{kV}$ spray voltage, 40 arbitrary units (AU) of sheath gas, $10 \mathrm{AU}$ of auxillary gas, $0 \mathrm{AU}$ of sweep gas, $275^{\circ} \mathrm{C}$ vaporizer temperature and an ion transfer capillary temperature of $320^{\circ} \mathrm{C}$. Analytes were detected using a full-scan data-dependent-MS ${ }^{2}$ acquisition procedure. Full-scan data were acquired between $450-1350 \mathrm{~m} / \mathrm{z}$ at 120000 resolution (full width half maximum at $200 \mathrm{~m} / \mathrm{z}, \mathrm{FWHM}_{200 \mathrm{~m} / \mathrm{z}}$ ) in profile mode, using: $1 \mathrm{e}^{5}$ auxillary gain control (AGC) target, $50 \mathrm{~ms}$ maximum ion injection time, 1 microscan, and wide quadrupole isolation. Tandem mass spectrometry data were acquired at 15000 resolution $\left(\mathrm{FWHM}_{200 \mathrm{~m} / \mathrm{z}}\right)$ in centroid mode for the top-3 ions from the preceding full-scan, using: $1 \mathrm{Da}$ quadrupole isolation width and $0 \mathrm{Da}$ isolation offset; $1 \mathrm{e}^{4}$ AGC target; $22 \mathrm{~ms}$ maximum ion injection time; $2 \mathrm{e}^{4}$ ion intensity threshold. For each target ion, higher-energy C-trap dissociation (HCD) $\mathrm{MS}^{2}$ spectra were acquired, independently, at normalised collision energies of 15, 30 and $45 \%$, followed by addition of the target ion's $\mathrm{m} / \mathrm{z}$ value to the dynamic exclusion list for 8 seconds. An exclusion list, generated from a solvent blank analysed at the start of the acquisition sequence, was used to prevent the top-100 background ions, detected in 5-min intervals throughout the 42-minute method, from triggering $\mathrm{MS}^{2}$ scans. An inclusion list was used to guide $\mathrm{MS}^{2}$ data acquisition and included the $\mathrm{m} / \mathrm{z}$ values for all compounds in CyanoMetDB ${ }^{[19]}$ within the full scan $m / z$ window for $[\mathrm{M}+\mathrm{H}]^{+}$ and $[\mathrm{M}+2 \mathrm{H}]^{2+}$ ion forms. When fewer than $3 \mathrm{~m} / \mathrm{z}$ values on the inclusion list were detected above the $\mathrm{MS}^{2}$ intensity threshold in the preceding full-scan, $\mathrm{MS}^{2}$ data were instead acquired for the most intense ion(s).

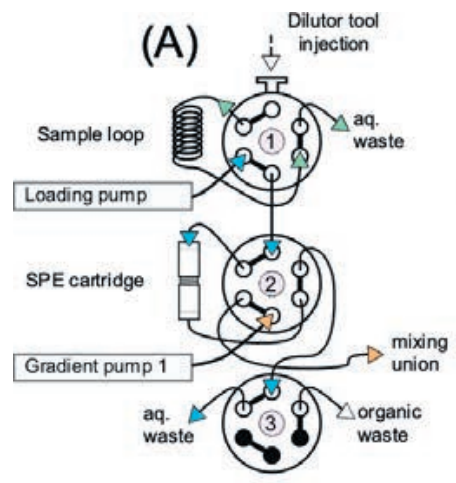

(B)

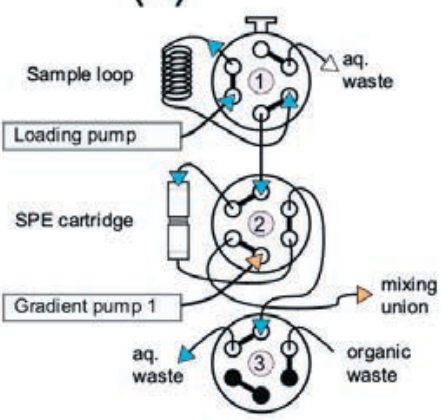

(C)

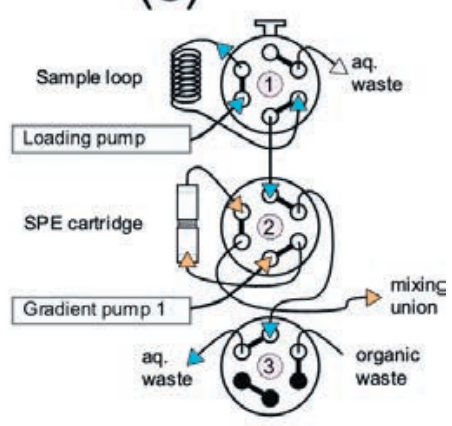

Fig. 2. Schematic representation of the online-SPE HPLC-HRMS/ MS configuration including: $(A)$ sample loading and analysis, in which a fresh sample is loaded into the sample loop using the dilutor tool while LC-MS analysis is performed for the previously enriched sample; (B) sample enrichment, in which the sample in the sample loop (loaded in step 'A') is pumped over the online-SPE cartridge for analyte enrichment, while LC-MS analysis continues for the previously loaded sample; (C) sample elution and loop washing, in which the sample constituents enriched on the SPE cartridge in step ' $\mathrm{B}$ ', are eluted towards the analytical LC column while the sample loop is rinsed in preparation for loading of the next sample.

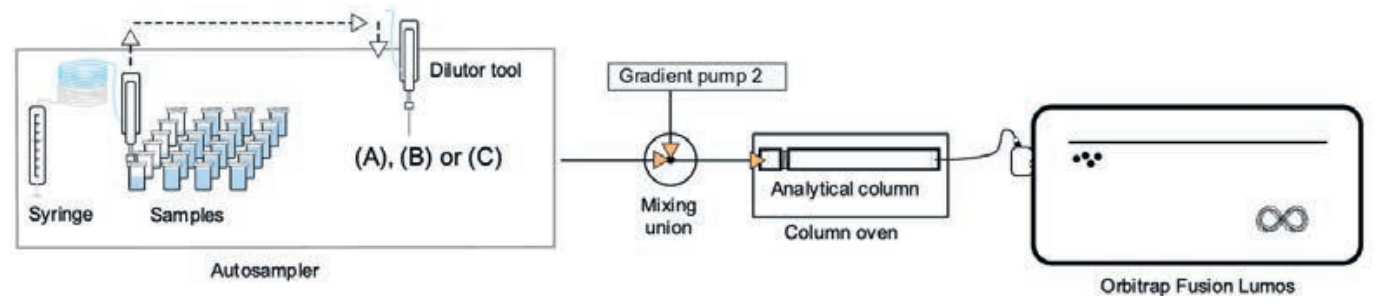




\subsection{Online-SPE HPLC-HRMS/MS Validation and Data Processing}

For validation of the online-SPE HPLC-HRMS/MS method, an analysis sequence was setup over five consecutive days, as follows: one full nanopure water-based calibration curve was analysed on days 1, 2 and 3, while three full nanopure water-based calibration curves were analysed on day 4; one full matrix-based calibration curve was analysed on days 1 and 3, and three matrix-based calibration curves were analysed on day 5; triplicate lake water samples, collected on a given date from a given lake, were analysed on days 1, 2 and 3, following the analysis of calibration curves. Nanopure water blanks were injected after each calibration curve and after each set of triplicate lake water samples.

\subsubsection{Data Processing}

LC-MS/MS data files were processed using Compound Discoverer v3.1. Herein, chromatographic peaks and associated MS/MS spectra were extracted from instrumental raw files using manufacturer-recommended settings for Tribrid-type mass spectrometers ( $5 \mathrm{ppm}$ mass tolerance, $30 \%$ intensity tolerance, 50000 minimum peak intensity). Next, chromatographic peaks were grouped across samples into so-called 'Compounds' using a $12 \mathrm{~s}$ retention time tolerance and $5 \mathrm{ppm} \mathrm{m/z} \mathrm{tolerance,} \mathrm{with-}$ out retention time correction. A gap-filling procedure, based on re-evaluation of raw data, was used to fill in any missing peak areas for each Compound and sample combination. Identities were thereafter assigned to 'Compounds' based primarily on comparison of experimental MS/MS spectra to the mzCloud library (10 ppm precursor and fragment mass tolerances, $50 \%$ match factor threshold, matched activation type with $20 \%$ energy match tolerance). Identities were secondarily assigned based on comparison of HRMS data to a CyanoMetDB mass list (5 ppm precursor mass tolerance, retention time tolerance 'false'). Finally, all assigned identities were manually inspected, and where necessary adjusted, to ensure that target cyanopeptides were assigned correctly - here, calibrant samples enabled high-confidence identity assignment.

An in-house Python script (v 3.8.10, including SciPy v1.7.1, Numpy 1.21.2, Matplotlib-base v3.4.3, Pandas v1.3.2, statsmodels 0.12 .2 ) was used for downstream data processing and analysis procedures. This included extraction (SQLalchemy 1.4.1) and subsequent summing of all peak areas from the Compound Discoverer results file associated with a given Compound and sample combination. Sample metadata was merged with the resulting peak matrix and duplicated peak areas resolved (summing of duplicated peak areas associated with a single compound identifier for a given sample, followed by retaining only the largest peak area in instances where more than 1 compound identifier was assigned to a unique target compound). Peak areas were then filtered to retain only those detected in at least $50 \%$ of a given sample type, i.e. lake-matrix calibrant, nanopure water calibrant, lake sample, blanks, etc. The resulting peak matrix was used to establish method performance metrics, as described below.

\subsubsection{Permutation-based Hypothesis Testing}

When establishing calibration curves, permutation-based hypothesis testing was used to assess the null hypothesis that raw peak areas for cyanopeptide-spiked calibrant solutions came from the same 'population' as non-spiked ( $0 \mathrm{ng} / \mathrm{L})$ calibrant solutions, i.e. that they were indistinguishable from one another. For each cyanopeptide, permutation hypothesis testing was performed 1e4 times per cyanopeptide, per concentration level, to generate a set of 'permuted test statistics', though less repetition would have been sufficient given the number of samples used in this study. The $p$-value of the permutation procedure was calculated as the proportion of 'permuted test statistics' that were equal to, or greater-than, the 'observed test statistic' (i.e. akin to a one-sided parametric $t$-test). If the $p$-value was less-than 0.01 , the null hypothesis was rejected. To account for multiple-testing errors, BenjaminiHochberg correction was applied to calculated $p$-values on a compound-by-compound basis. The same procedure was applied for blank-filtering of lake sample cyanopeptide peak areas.

\subsubsection{Generating Calibration Curves and Estimation LOD and $L O Q$}

Linear least-squares regression analysis (statsmodels v0.12.2, including constant) was used to generate calibration curves for each of the detected method validation compounds, in each calibrant matrix type. Models built using raw peak areas and calibrant concentrations generally showed heteroscedascity of residuals (i.e. increasing variance with increasing concentration). To address this, peak areas and calibrant concentrations were natural log-transformed prior to regression analysis. Data were excluded from the linear least-squares fit procedure if: 1) permutation-based hypothesis testing failed to reject the null hypothesis that peak areas recorded in spiked and nonspiked (i.e. $0 \mathrm{ng} / \mathrm{L}$ cyanopeptide calibrant solution) calibrant solutions came from the same 'population', as detailed above, or; 2) the absolute Studentised residual for a given sample was greater-than 3, or; 3 ) fewer-than 3 replicates were available (after filtering based on 1 and 2) for calculation of both repeatability and intermediate precision, at a given calibrant concentration level.

For each cyanopeptide, instrumental limits of detection (iLOD) and quantification (iLOQ) were estimated from the associated nanopure water-based calibration curve (regression) model according to Eqn. (1), below. The lower bound for the calibrations was set at the first calibration level equal to, or exceeding, the estimated LOD for each compound and for which at least three replicates were available for evaluating both repeatability (intra-day precision) and intermediate (i.e. inter-day) method precision. Methodological LOD and LOQ values were likewise estimated, albeit using matrix-matched calibration models.

$$
e^{\left(\frac{\left(\operatorname { l n } \left[e^{\left.\left(a+\left[k \times \theta_{\text {resids }}\right)-e^{a}\right]-c\right)}\right.\right.}{m}\right)}= \begin{cases}\text { iLOD or } m L O Q, & k=3.3 \\ \text { iLOQ or } m L O Q, & k=10\end{cases}
$$

where: $a$ is the median of natural log-transformed peak areas for $0 \mathrm{ng} / \mathrm{L}$ calibrants; $m, c$ and $\theta_{\text {resids }}$ are the slope parameter, intercept and standard deviation of relative residuals of the linear regression model, respectively; $k$ is a constant.

\subsubsection{Accuracy, Intra-day and Inter-day Precision, Matrix Effects, Recovery}

Accuracy, I, was calculated for each cyanopeptide and calibration matrix type combination according to the Eqn. (2):

$$
I=\left[\frac{\hat{c}}{E(c)} * 100\right]
$$

where, $\hat{c}$ is the estimated concentration from the corresponding calibration model, and $E(c)$ is the expected concentration of a cyanopeptide in a given calibrant solution.

Intra-day precision (i.e. repeatability) was calculated from peak areas of at least three nanopure water-based calibrants and three matrix-based calibrants, with each set measured over a single day. Inter-day imprecision (i.e. intermediate precision) was calculated using peak areas from the first calibration curve replicate analysed on: days 1, 2, 3 and 4 for nanopure water-based calibration curves; days 1, 3 and 5 for matrix-based 
calibration curves. Intra-day and inter-day precision were calculated as the percent coefficient of variation $(\% \mathrm{CV})$ of peak areas. Given that calibration curves were constructed using $\ln$-transformed peak area and concentration data, the following equation was used to calculate $\% C V$ on the untransformed scale:

$$
\% \mathrm{CV}=\sqrt{e^{\sigma_{l n}^{2}-1}}
$$

where $\sigma_{l n}^{2}$ is the variance of estimated concentrations on the $\ln$-transformed scale and $e$ is Euler's number.

Matrix effects were calculated as the ratio of lake matrix and nanopure water-based (denominator) calibration slopes, multiplied by 100 . To assess absolute recovery, three additional nanopure water-based calibration curves were prepared from working solutions (without GF/F syringe filtration) and analysed using the described online-SPE-HPLC-HRMS/MS method. Afterwards, the system was reconfigured to direct injection mode and $20 \mu \mathrm{L}$ aliquots injected directly onto the analytical LC column, without prior online-SPE enrichment, to generate three HPLC-HRMS/MS nanopure water-based calibration curves. Given that the HPLCHRMS/MS method had no online-SPE elution step, a slightly modified binary linear gradient was used for analyte elution from the HPLC column, as follows: 0/20/50/70/100/100/0/0\% $\mathrm{B}$ at 0/0.5/4.5/20.4/20.5/25/25.1/30 min. For each cyanopeptide, absolute recovery was calculated at each concentration level as the ratio of the average peak area recorded using the online-SPEHPLC-HRMS/MS method (numerator) to that recorded using the HPLC-HRMS/MS (denominator) method, accounting for differences in mol loaded during the latter method.

\subsection{Identification and Quantification of Cyanopeptides in Lake Samples}

Target compounds were identified in lake samples based on exact mass $(<5 \mathrm{ppm}$ mass error) and accurate isotopic pattern of the precursor ion, as well as matching of the measured retention time and MS/MS fragmentation data against reference standards or bioreagents. The peak areas for identified targets, for each com- bination of lake and sampling date, were 'blank filtered', meaning that they were compared to the corresponding peak areas from the $0 \mathrm{ng} / \mathrm{L}$ lake matrix standard using a permutation testing procedure (described above). Associated peak areas were retained only if the adjusted $p$-value (Benjamini-Hochberg correction across all estimated p-values) was $\leq 0.01$. The concentrations in lake samples were finally calculated from the corresponding lake matrix-based calibration curve.

\section{Results and Discussion}

A total of 17 cyanopeptides, spanning 5 distinct structural classes, were used to validate the online-SPE HPLC-HRMS/MS method as a high-throughput and sensitive tool for monitoring multi-class cyanopeptides in lake waters. For all compounds, baseline chromatographic peak widths were generally less than $30 \mathrm{~s}$, with retention times ranging between 19-35 min, corresponding to 6-22 min retention on the analytical column (Fig. 3, Table 2). Method performance metrics including linear range, accuracy, intra- and inter-day precision, matrix effects, recovery and carryover were estimated from nanopure water- and lake matrix-based calibration curves, each being generated from calibrants injected over the course of the 5-day validation procedure.

\subsection{Calibration Range, Linearity, $m L O D$ and $m L O Q$}

The coupling of online-SPE with HPLC-HRMS/MS enables large volume injection and automated clean-up of surface water samples, prior to in-depth analysis. This process is both simple and reproducible, while offering significant sensitivity improvements over direct injection of lake water samples onto the analytical column where injection volumes are limited to approx. 5-100 $\mu \mathrm{L}$. In addition, matrix interferents, which can adversely impact detection sensitivity and reproducibility, are injected alongside target analytes for direct injection methods. The need for sensitivity and the importance of removing matrix interferents, underpins the routine use of laborious manifold-based SPE in existing cyanopeptide analysis methods. ${ }^{[20]}$

Sensitivity of the online-SPE method was estimated from calibration curves, the upper bounds were approx. $200 \mathrm{ng} / \mathrm{L}$ for $\left[\mathrm{D}-\mathrm{Asp}^{3},(E)-\mathrm{Dhb}^{7}\right] \mathrm{MC}-\mathrm{RR}$ and $1000 \mathrm{ng} / \mathrm{L}$ for all other cyanopeptides. The lower bound for calibration curves, meanwhile, was defined as the first calibration level that was equal to or exceed-

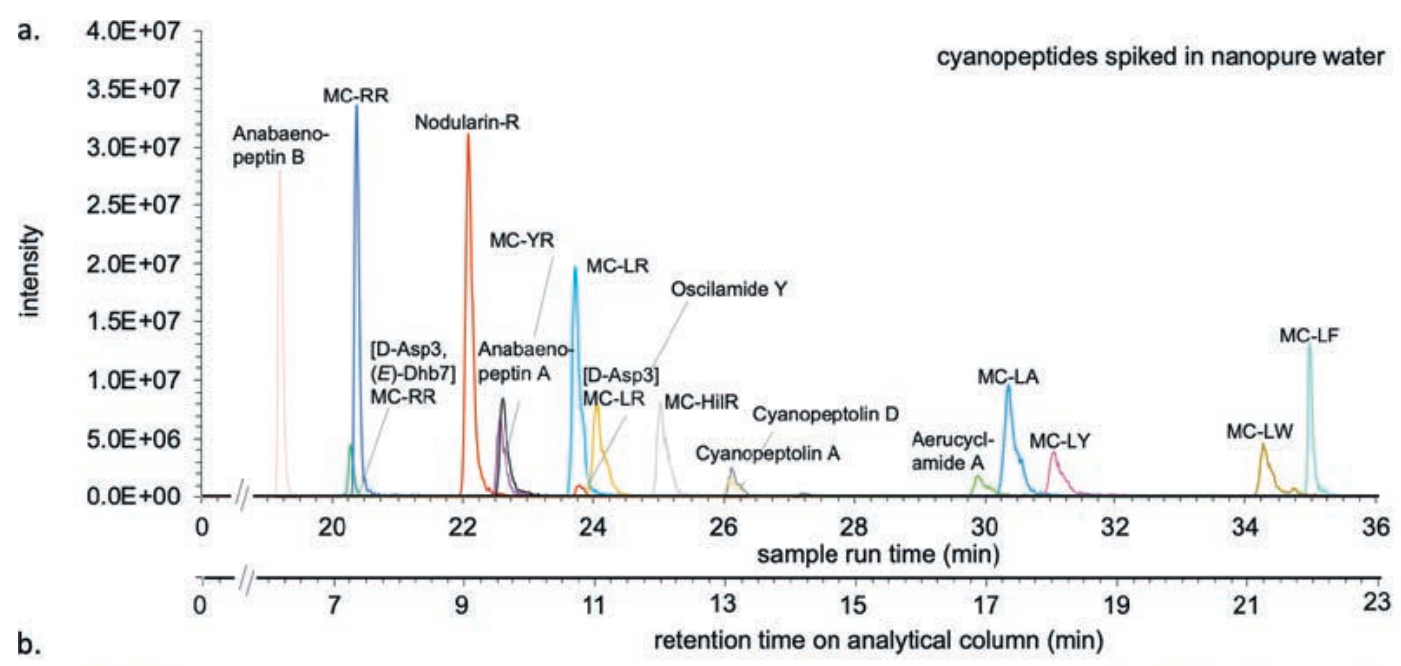

Fig. 3. Extracted ion chromatograms (EICs) of protonated precursors overlayed for $(A)$ cyanopeptides spiked (50 $\mathrm{ng} / \mathrm{L}$ ) into nanopure water and (B) identified in natural lakes samples showing the sample run time of the onlineSPE-LC-HRMS/MS run and the corresponding retention time on the analytical column.

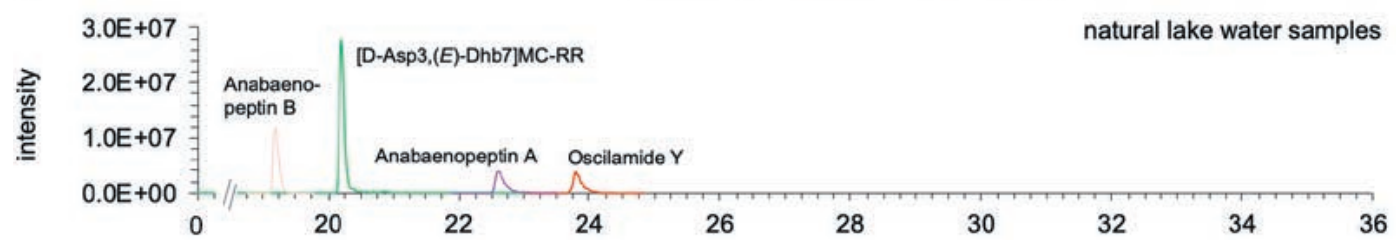


Table 2. Online-SPE HPLC/HRMS/MS method performance parameters including: calibration range (ng/L) and correlation coefficient ( $\left.\mathrm{r}^{2}\right)$; instrument limits of detection (iLOD) and quantification (iLOQ) derived from nanopure water-based calibration curves; method limit of detection (mLOD) and quantification (mLOQ), derived from matrix-matched calibration curves; matrix effects (\%); absolute retention time (RT) in minutes and RT relative to $\mathrm{MC}-\mathrm{LR}\left(\mathrm{RT}_{\text {rel }}\right)$; instrument response factor relative to $\mathrm{MC}-\mathrm{LR}\left(\mathrm{RF}_{\text {rel }}\right)$ in percent.

\begin{tabular}{|c|c|c|c|c|c|c|c|c|c|c|}
\hline Compound & $\begin{array}{l}\text { Calibration } \\
\text { range in lake } \\
\text { matrix }(\mathrm{ng} / \mathrm{L})^{\mathrm{a}}\end{array}$ & $\mathbf{r}^{2}$ & $\begin{array}{l}\text { iLOD } \\
(\mathrm{ng} / \mathrm{L})\end{array}$ & $\begin{array}{l}\text { iLOQ } \\
(\mathrm{ng} / \mathrm{L})\end{array}$ & $\begin{array}{l}\text { mLOD } \\
(\mathrm{ng} / \mathrm{L})\end{array}$ & $\begin{array}{l}\text { mLOQ } \\
(\mathrm{ng} / \mathrm{L})\end{array}$ & $\begin{array}{l}\text { matrix } \\
\text { effect } \\
(\%)\end{array}$ & $\begin{array}{l}\mathbf{R T}^{\mathbf{b}} \\
(\min .)\end{array}$ & $\mathbf{R T}_{\text {rel }}$ & $\begin{array}{l}\mathbf{R F}_{\text {rel }} \\
(\%)^{\mathbf{c}}\end{array}$ \\
\hline Aerucyclamide A & $20-1000$ & 0.996 & 0.5 & 1.8 & 2.1 & 7.8 & -5 & 29.93 & 1.26 & 23.8 \\
\hline Anabaenopeptin A & 10-990 & 0.997 & 0.1 & 0.4 & 0.9 & 3.3 & 0 & 22.63 & 0.95 & 54.7 \\
\hline Anabaenopeptin B & 10-992 & 0.997 & 0.2 & 0.8 & 0.5 & 1.9 & -9 & 19.2 & 0.81 & 53.4 \\
\hline Cyanopeptolin A & 20-991 & 0.992 & 1.2 & 5.3 & 5.1 & 21.2 & -1 & 26.09 & 1.10 & 20.2 \\
\hline Cyanopeptolin D & 50-986 & 0.970 & 1.1 & 4.2 & 16.6 & 94.3 & 1 & 26.07 & 1.09 & 14.1 \\
\hline MC-HilR & 10-986 & 0.998 & 0.2 & 0.7 & 0.3 & 1.1 & -3 & 25.02 & 1.05 & 135.7 \\
\hline MC-LA & $11-1008$ & 0.997 & 0.1 & 0.5 & 0.3 & 1.2 & -5 & 30.49 & 1.28 & 107.8 \\
\hline MC-LF & 20-992 & 0.996 & 0.3 & 1 & 0.6 & 2.4 & -8 & 35.04 & 1.47 & 111.1 \\
\hline MC-LR & $11-1007$ & 0.998 & 0.1 & 0.6 & 0.5 & 1.9 & -4 & 23.83 & 1.00 & 100.0 \\
\hline MC-LW & $10-996$ & 0.993 & 4.2 & 20.3 & 1.4 & 6.6 & -24 & 34.36 & 1.44 & 80.9 \\
\hline MC-LY & 10-992 & 0.997 & 0.1 & 0.5 & 1.0 & 3.7 & 1 & 31.17 & 1.31 & 59.2 \\
\hline MC-RR & $11-1069$ & 0.994 & 0.1 & 0.4 & 7.9 & 33.8 & -1 & 20.38 & 0.86 & 110.2 \\
\hline MC-YR & 20-990 & 0.996 & 0.2 & 0.6 & 1.4 & 5.2 & -3 & 22.56 & 0.95 & 47.0 \\
\hline Nodularin-R & $2-988$ & 0.998 & $<0.1$ & 0.1 & 0.4 & 1.4 & -2 & 22.88 & 0.96 & 21.5 \\
\hline Oscillamide Y & $124-990$ & 0.927 & 0.8 & 2.7 & 40.2 & 260.9 & 5 & 23.8 & 1.00 & 6.9 \\
\hline $\begin{array}{l}{\left[\mathrm{D}-\mathrm{Asp}^{3},(\mathrm{E})-\mathrm{Dhb}^{7}\right]} \\
\mathrm{MC}-\mathrm{RR}\end{array}$ & $2-199$ & 0.992 & 0.1 & 0.5 & 0.9 & 5.2 & -12 & 20.28 & 0.86 & 84.6 \\
\hline$\left[\mathrm{D}-\mathrm{Asp}^{3}\right] \mathrm{MC}-\mathrm{LR}$ & $1-995$ & 0.998 & 0.2 & 0.8 & 0.8 & 3.0 & -2 & 24.12 & 1.01 & 86.5 \\
\hline
\end{tabular}

a The effective linear working range of the method, including only those calibrant levels that exceed the mLOD and that were retained after permutationbased hypothesis testing (i.e. blank filtering); babsolute retention time, RT, corresponds to the run time of the sample on the online-SPE-HPLC-MS/ MS, the effective retention time on the analytical column is equal to RT minus $13 \mathrm{~min}$; ${ }^{\mathrm{m}}$ edian response factor, calculated from all ratios between the median peak area of a compound to that of the median peak area of MC-LR across approximately identical concentration levels and after correction for differences in recovery.

ed the LOD. Across all compounds, lower bounds for nanopure water-based calibration curves ranged between 0.2 and $10 \mathrm{ng} / \mathrm{L}$, while for lake matrix-based calibration curves lower bounds ranged from 0.4 to $124 \mathrm{ng} / \mathrm{L}$. Within these bounds, excellent linearity was achieved for all nanopure calibration curves $\left(\mathrm{r}^{2} \geq\right.$ 0.996, exception MC-LW: $\left.\mathrm{r}^{2}=0.981\right)$. For matrix-based calibration curves linearity was also acceptable within these bounds $\left(\mathrm{r}^{2}\right.$ $\geq 0.992$, exception cyanopeptolin $\mathrm{D}: \mathrm{r}^{2}=0.970$ and oscillamide Y: $\mathrm{r}^{2}=0.926$ )

Instrumental and methodological LODs and LOQs (Table 2) were respectively estimated from the standard deviation of residuals of the nanopure water and lake matrix-based calibration curves, according to Eqn. (1). Instrumental LODs ranged from 0.1-4.2 ng/L and instrumental LOQs from 0.1-20.3 ng/L. Methodological LODs and LOQs meanwhile, which consider the effects of sample preparation steps such as freezing, thawing and filtering, as well as matrix effects ranged from $0.3-40.2 \mathrm{ng} / \mathrm{L}$ and 1.1-261 ng/L, respectively. Overall, the online-SPE method was sensitive enough to enable monitoring and quantification of cyanopeptides in surface waters in the low ng/L-range, which is four to hundreds of times lower than the water quality guidelines, e.g. $1 \mu \mathrm{g} / \mathrm{L}$ for Microcystin-LR. ${ }^{[7]}$ This in turn opens the possibility for earlier detection of cyanobacterial toxins and secondary metabolites, such as at the onset of a cyanobacterial bloom. To achieve comparable mLOD and mLOQ values with traditional methods, one would need to collect, store and process much larger volumes of lake water, e.g. 0.5-1 L, for purification and enrichment by offline-SPE before LC-MS analysis.

\subsection{Accuracy, Intra-day and Inter-day Precision}

Besides offering excellent cyanopeptide detection sensitivity, online-SPE HPLC-HRMS/MS is also a highly reproducible and comparatively high-throughput approach. The combination of automated loading of aqueous samples and direct elution of analytes into the LC-MS, promises high reliability of analytical results because adverse impacts from manual handling during offline-SPE are eliminated. We calculated the accuracy of the online-SPE HPLC-HRMS/MS method for all target cyanopeptides as the average of the ratio of a calibrant's estimated concentration, as derived from the lake matrix-based calibration curve, to that of its expected concentration. The average accuracy values of the online-SPE method ranged between 85 and $116 \%$ across all matrix-matched calibration levels. For all calibration levels at or above estimated mLOQs (Fig. 4A), the $95 \%$ confidence intervals 
for these average accuracy values ranged between 67 and $137 \%$, of which $98 \%$ were between $70-130 \%$, indicating adequate methodological accuracy for quantitative analysis of target cyanopeptides in lake waters. Comparable average accuracy values were recorded for cyanopeptides measured in nanopure water, where values ranged between $85-117 \%$ (70-138\% when considering the $95 \%$ confidence interval for each value).

Intra-day precision (i.e. repeatability) and inter-day precision (i.e. intermediate precision) were estimated at each matrix-based calibration level based on the relative standard deviation of calibrant peak areas analysed over a single day, or over multiple days, respectively. As shown in Fig. 4C and 4D, both intra- and inter-day precision were $\leq 20 \%$ for most target compounds and matrix-matched calibration levels, indicating adequate methodological precision. ${ }^{[21]}$ Here, the anabaenopeptin oscillamide $\mathrm{Y}$ was the only notable exception, with inter-day precision of $18-38 \%$. We hypothesise that matrix-induced compound degradation underpinned these elevated values. This is supported by the fact that peak areas for oscillamide $\mathrm{Y}$ when measured in nanopure water calibrants remained essentially constant throughout the validation experiment (nanopure standards were analysed on 4 out of 5 days), with intra- and inter-day precision $<11 \%$, suggesting no obvious decrease in detector sensitivity or SPE efficiency towards oscillamide Y during this time. Meanwhile, intra-day precision
(A)

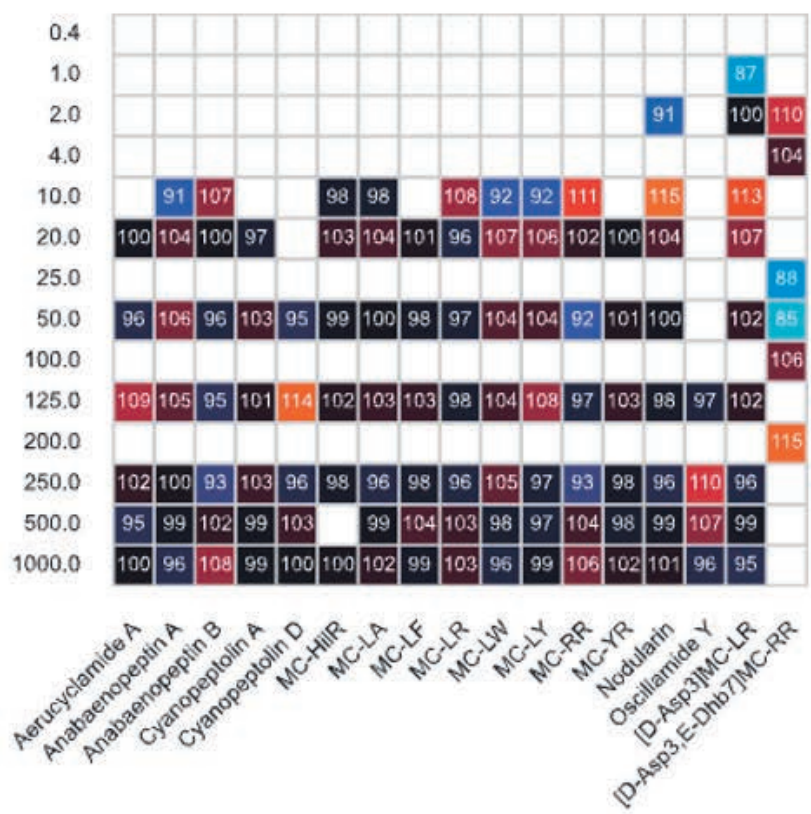

(C)
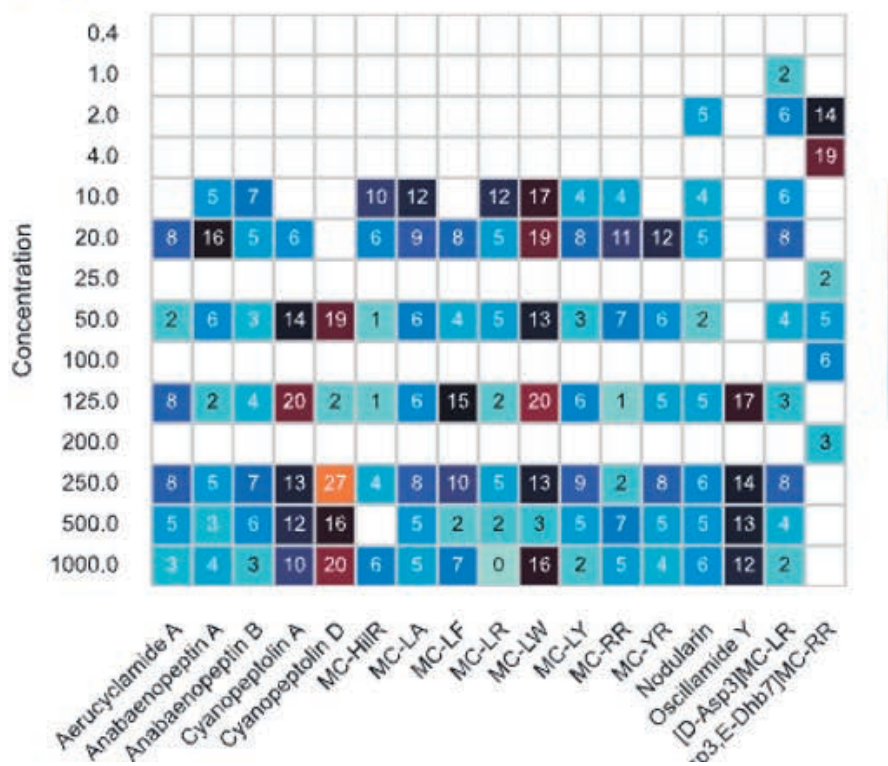

(B)
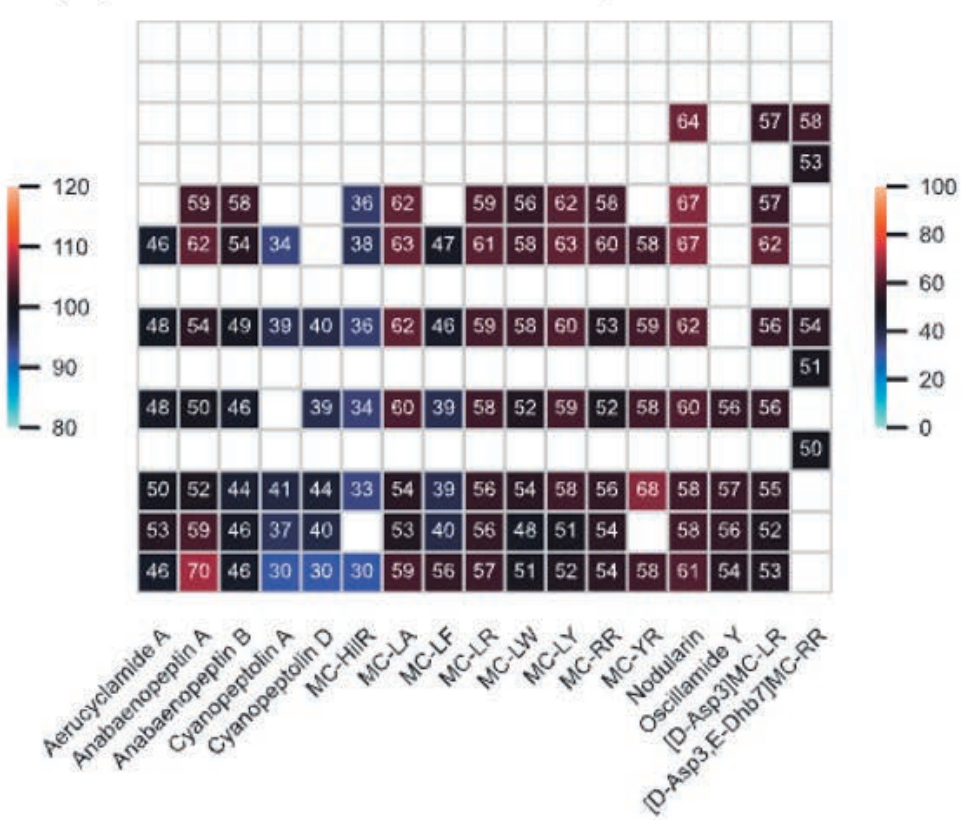

(D) Inter-day precision - lake matrix
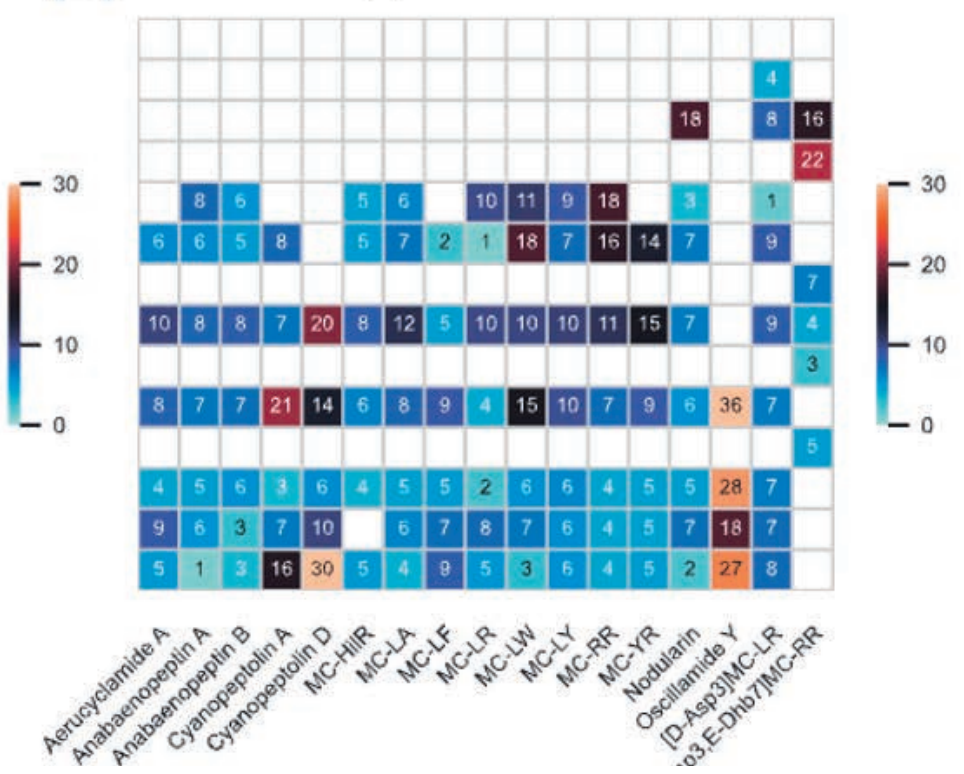

Fig. 4. (A) accuracy, (B) recovery, corresponding to recovery between injection and detection in the online-SPE HPLC-HRMS/MS method (i.e. excluding any prior sample filtration procedures) (C) intra-day precision ( $n=3$ and (D) inter-day (intermediate) precision $(n=3)$ metrics for 17 target cyanopeptides measured in lake matrix-based calibrants. Precision metrics are presented as relative standard deviation of peak areas, while recovery reflects the ratio of the median peak area measured by online-SPE-HPLC-HRMS/MS, to that measured through direct injection of an equivalent concentration on to the analytical column without SPE enrichment. For visualisation purposes only, concentrations for all compounds except for [D-Asp3,(E)-Dhb7]MC-RR have been rounded to the nearest value in the list: 1, 2, 10, 20, 50, 125, 250, 500 and $1000 \mathrm{ng} / \mathrm{L}$. Nominal concentrations for [D-Asp3,(E)-Dhb7]MC-RR have been rounded to the nearest value in the list: $0.2,0.4,2,4,10,25,50,100$ and $200 \mathrm{ng} / \mathrm{L}$. 
of oscillamide Y peak areas when measured in lake matrix-based calibrants were comparably consistent at $<20 \%$, suggesting adequate within-day stability of peak areas. Finally, when looking at the raw peak areas for oscillamide Y measured in lake-matrix calibrants over the course of the validation experiment, a decrease of approximately $40 \%$ was observed, while peak areas for co-spiked cyanopeptides showed no such trend. Collectively, these points amount to the first quantitative demonstration of oscillamide Y's instability in lake matrix and serve as a reminder of the importance of considering compound stability over the course of extended analytical runs. Given that the cyanopeptide composition of a sample is often unknown before analysis, nor is it known how any such cyanopeptides might be chemically affected by matrix constituents, we recommend to include quality control samples, generated by pooling aliquots of all or a subset of study samples, and inject those periodically throughout the sequence. This procedure adopted from metabolomics research enables monitoring of analytical precision; signal (peak area) correction for analytical drift and (modest amounts of) compound degradation, and; supports downstream data processing procedures such as feature filtering and signal normalisation. ${ }^{[22]}$

\subsection{Matrix Effects, Recoveries and Carryover}

Surface waters contain a diverse array of dissolved minerals and organic matter of natural and anthropogenic origin, which can cause enhancement or suppression of ionisation processes prior to MS detection, leading to quantitative inaccuracies. We assessed the extent of these so-called matrix effects following clean-up of samples by online-SPE, using the ratio of slope parameters for lake Greifensee matrix-matched and nanopure water-based calibration curves. This revealed only minor matrix effects, for the majority of target cyanopeptides, with values ranging between -10 and $+5 \%$ (Table 2). [D-Asp $\left.{ }^{3},(E)-\mathrm{Dhb}^{7}\right] \mathrm{MC}-\mathrm{RR}$ showed slightly larger ion suppression effects at $-12 \%$, while for MC-LW matrix effects amounted to $-24 \%$. Given the inherent complexity of environmental matrices in such a lake water, these matrix effects were deemed more-than adequate. We acknowledge, however, that different matrices may result in differing extents of matrix effects. Correction for these effects would ideally be pursued through internal standardization of analyte peak areas against those of stable isotope labelled reference standards, though such standards are scarcely available for cyanopeptides. As a minimum, therefore, we recommend inclusion of matrix-spiked calibration solutions to assess and account for the matrix effects in each analysis sequence.

While SPE reduces matrix effects, it also bears the risk of incomplete cyanopeptide recovery due to: 1) saturation of the SPE cartridge and subsequent analyte breakthrough, 2) losses during SPE cartridge washing, and 3) incomplete elution from the SPE cartridge. Absolute recoveries associated exclusively with the online-SPE component of the online-SPE HPLC-HRMS/ MS method, were estimated from the ratio of peak areas for nanopure water-based calibrants analysed using this method, to those measured using an equivalent HPLC-HRMS/MS method without the online-SPE enrichment phase (scaled to match injected quantity of cyanopeptides). As shown in Fig. 4B, absolute recoveries ranged between $30 \%$ and $70 \%$ (median $=56 \%$ ) across all target cyanopeptides and calibration levels. These values are in close agreement with recovery values reported for cyanopeptides enriched using bench-top Oasis HLB cartridges. [20b,23] No obvious relationship between the concentration loaded on to the SPE column and observed recovery values was apparent, suggesting neither SPE column saturation nor cyanopeptide breakthrough as major causes of loss during online-SPE, within the range of loadings tested. We also observed rapid cyanopeptide elution from the SPE sorbent towards the HPLC column (data not shown).
While striving to maximize recovery of cyanopeptide from the online-SPE step, it is pertinent to highlight that the sample filtration prior to analysis can cause significant loss of cyanopeptide, as demonstrated previously. ${ }^{[18 b, 24]}$ In the work presented here, lake matrix-based calibrants and lake samples were passed through $\mathrm{GF} / \mathrm{F}$ filters prior to analysis. We estimated loss by filtration by spiking lake matrix with standards either before or after filtration. Unlike Fayad et al. who reported $0 \%$ recovery of MC-RR, MC-YR and MC-LR after glass fibre filtration, ${ }^{[24]}$ all target microcystins in the present study were recovered with $>77.8 \%$ efficiency. Partial differences in filter material and matrix composition may have contributed to these disparate results, though we suspect sample $\mathrm{pH}$ played a more significant role; Fayad et al. acidified samples $(\mathrm{pH} \sim 2)$ prior to filtration, while samples in the present study were adjusted to $\mathrm{pH} \sim 9$. With regards to recovery of other target cyanopeptides in the presented study, filtration recovery values were (to 2 s.f.): $94 \%$ for aerucyclamide; $95 \%$ for anabaenopeptin A; $98 \%$ for anabaenoptpin B; $70 \%$ for cyanopeptolin A; $60 \%$ for cyanopeptolin D; $86 \%$ for nodularin-R and $49 \%$ for oscillamide $\mathrm{Y}$. Careful consideration needs to be paid to the effects of sample filtration on analyte recovery, considering not only the filter materials used, but also sample chemistry and filtration conditions applied.

In addition to matrix effects and incomplete cyanopeptide recovery during SPE and filtration, the re-use of a single SPE cartridge for enrichment of a sequence of samples bears the risk of quantitative inaccuracies due to potential carryover effects. To assess the magnitude of such effects, we calculated the ratio of peak areas for cyanopeptides detected in the highest corresponding matrix-matched calibrants (denominator) to those in nanopure water 'blanks' (numerator) injected immediately thereafter. For all 17 target cyanopeptides, carryover effects were consistently below $0.9 \%$. These values, while low, are not zero and as such we recommend minimizing the impact of carryover on quantitative analyses by injecting one 'blanking' nanopure water sample after each block of related samples, e.g. replicate samples, or two nanopure water samples after the analysis of highly concentrated samples and calibration standards, according to previous onlineSPE-based cyanotoxin analysis methods. ${ }^{[25]}$ In experiments beyond those reported in this work, we have used the method to analyse over 250 calibrant and aqueous samples, without needing to replace the SPE cartridge due to performance degradation.

To summarise, validation of the described online-SPE HPLCHRMS/MS method has shown the method allows for quantitative monitoring of surface waters for 17 distinct cyanopeptides, spanning 5 unique structural classes. The method enables high-throughput screening, on account of automated sample preparation, while also supporting suspect and non-target cyanopeptide screening through HRMS/MS detection. While absolute recovery values were below $100 \%$ for the online-SPE HPLC-HRMS/MS method, other methodological metrics such as reproducibility, accuracy, sensitivity and matrix effects were generally excellent.

\subsection{Analysis of Lake Samples by Online-SPE-HPLC- HRMS/MS}

The online-SPE-HPLC-HRMS/MS method was applied to Swiss water samples from lake Greifensee, Zürichsee and Hallwilersee sampled between July and November 2019. Anabaenopeptins and one microcystin were detected in all lakes in the $\mathrm{ng} / \mathrm{L}$ range including anabaenopeptin $\mathrm{A}$, anabaenopeptin $\mathrm{B}$, oscillamide $\mathrm{Y}$ and $\left[\mathrm{D}-\mathrm{Asp}^{3},(E)-\mathrm{Dhb}^{7}\right] \mathrm{MC}-\mathrm{RR}$ (Table 3).

Oscillamide $Y$ was the cyanopeptide detected at the highest concentration of $355 \mathrm{ng} / \mathrm{L}$ (Greifensee, 13 August) but it was below the $\mathrm{mLOQ}$ in all other samples due to its high quantification limits. Data in Fig. 5 compares the total concentration of anabaenopeptins to the total concentration of microcystins only considering concentrations above the mLOQ. When $\left[\mathrm{D}-\mathrm{Asp}^{3},(E)-\mathrm{Dhb}^{7}\right] \mathrm{MC}-\mathrm{RR}$ was present, its concentration exceeded the total concentration of anabaenopeptins 


\begin{tabular}{|c|c|c|c|c|c|}
\hline Lake sample & (dd.mm) & Oscillamide Y & $\begin{array}{l}\text { Anabaeno- } \\
\text { peptin A }\end{array}$ & $\begin{array}{l}\text { Anabaeno- } \\
\text { peptin B }\end{array}$ & $\begin{array}{c}{\left[\mathrm{D}-\mathrm{Asp}^{3},(\boldsymbol{E})-\right.} \\
\left.\mathrm{Dhb}^{7}\right] \mathrm{MC}-\mathrm{RR}\end{array}$ \\
\hline \multirow[t]{5}{*}{ Greifensee } & 16.07 & $(81.6 \pm 51.3)^{\mathrm{a}}$ & n.d. \pm & n.d. \pm & n.d \pm \\
\hline & 13.08 & $354.9 \pm 88.4$ & $10.0 \pm 3.1$ & n.d. \pm & n.d \pm \\
\hline & 19.09 & $(170.6 \pm 5.2)^{\mathrm{a}}$ & $5.3 \pm 1.0$ & n.d. \pm & $(5.1 \pm 0.4)^{\mathrm{a}}$ \\
\hline & 15.10 & $(102.2 \pm 14.1)^{\mathrm{a}}$ & $3.5 \pm 0.2$ & $(1.4 \pm 0.0)^{\mathrm{a}}$ & $20.5 \pm 0.7$ \\
\hline & 05.11 & $(151.7 \pm 21.8)^{\mathrm{a}}$ & $5.8 \pm 0.6$ & $(1.7 \pm 0.1)^{\mathrm{a}}$ & $65.8 \pm 1.9$ \\
\hline \multirow[t]{2}{*}{ Zürichsee } & 04.09 & $(57.9 \pm 4.6)^{\mathrm{a}}$ & $7.1 \pm 0.7$ & n.d \pm & $7.0 \pm 0.6$ \\
\hline & 06.11 & $(163.1 \pm 46.6)^{\mathrm{a}}$ & $35.6 \pm 11.7$ & $17.5 \pm 6.5$ & $47.4 \pm 6.4$ \\
\hline \multirow[t]{3}{*}{ Hallwilersee } & 17.07 & $(93.8 \pm 2.5)^{\mathrm{a}}$ & $12.2 \pm 1.4$ & $5.9 \pm 0.6$ & $42.4 \pm 1.8$ \\
\hline & 18.09 & $(42.5 \pm 2.5)^{\mathrm{a}}$ & $6.4 \pm 1.1$ & $4.5 \pm 0.8$ & $22.0 \pm 0.7$ \\
\hline & 13.11 & $(122.7 \pm 33)^{a}$ & $29.2 \pm 6.4$ & $28.4 \pm 5.3$ & $59.8 \pm 7.3$ \\
\hline
\end{tabular}

Table 3. Quantification of cyanopeptides in lake samples from 2019 by online-SPE HPLC/ HRMS/MS method (ng/L \pm one standard deviation).

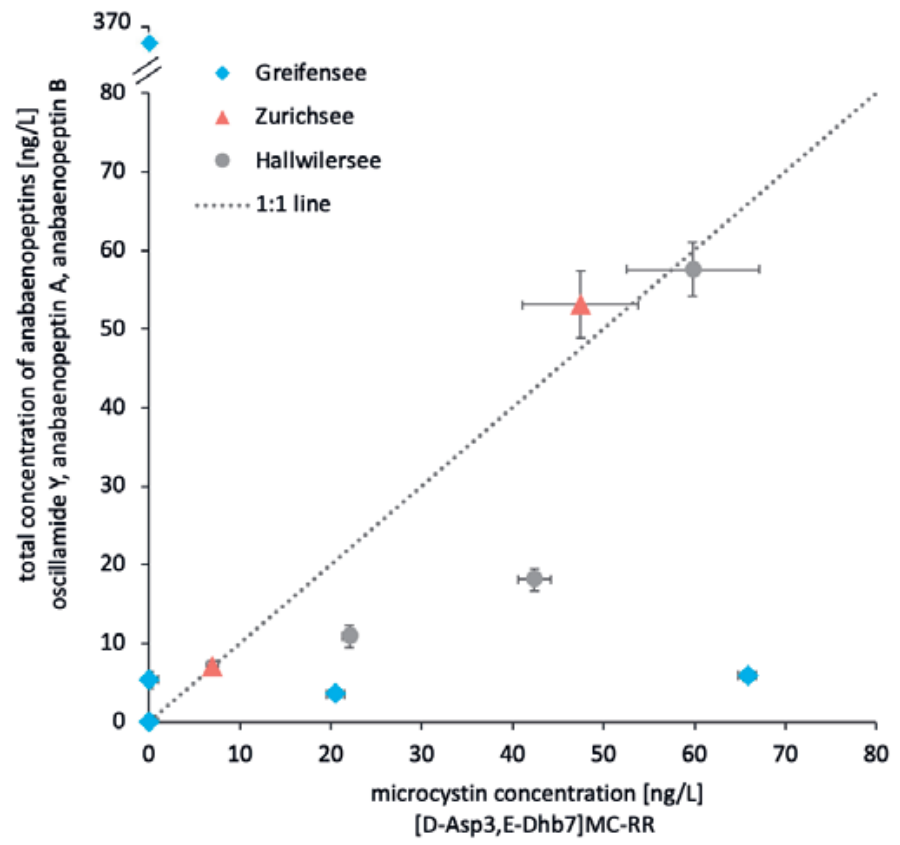

Fig. 5. Concentrations of freely dissolved cyanopeptides in lake water (ng/L) analysed by online-SPE-HPLC-HRMS/MS showing the total anabaenopeptide concentrations (sum of oscillamide $Y$, anabaenopeptin $A$, anabaenopeptin $B$ ) relative to the total microcystin concentration of [D-Asp3,(E)-Dhb7]MC-RR for samples from lake Greifensee (blue diamonds, $n=5$ ), Zürichsee (red triangles, $n=2$ ) and Hallwilersee (grey circles, $n=3$ ) as average value from triplicate field samples.

in several lake samples (data below 1:1 line). However, anabaenopeptins were also present in several samples even when no microcystins were detectable (data on the $\mathrm{y}$-axis at $\mathrm{x}=0$ ).

The highest concentration of freely dissolved microcystins detected was $65.8 \mathrm{ng} / \mathrm{L}$, well below the WHO guideline value of $1 \mu \mathrm{g} / \mathrm{L} .{ }^{[7]}$ While the commonly monitored MC-LR was absent in all tested samples, $\left[\mathrm{D}-\mathrm{Asp}^{3},(E)-\mathrm{Dhb}^{7}\right] \mathrm{MC}-\mathrm{RR}$ was the dominating variant of toxic microcystins. The detected cyanopeptides in the samples from 2019 in lake Hallwilersee are in agreement with previous data of anabaenopeptin $\mathrm{A}$, anabaenopeptin $\mathrm{B}$, oscillamide $\mathrm{Y}$ and $\left[\mathrm{D}-\mathrm{Asp}^{3},(E)-\mathrm{Dhb}^{7}\right] \mathrm{MC}-\mathrm{RR}$ detected in concentrated biomass samples in 2002-2005. [4e] Qualitatively, we identified the same cyanopeptides in the three lakes, which are known to be inhabited by the same cyanobacterium; Planktothrix rubescens. ${ }^{[4,66,26]}$ The results obtained for Swiss lakes are in line with findings for other European lakes inhabited by Planktothrix rubescens where demethylated microcystin-RR variants were regularly identified.[27]

\section{Conclusions and Implications}

We have presented the validation of an automated, online-SPE HPLC-HRMS/MS method for multi-class cyanopeptide analysis and demonstrated its application in detecting trace-levels of cyanopeptides in Swiss lake waters. The method is shown to be sensitive, accurate and reproducible, while offering two strong logistical advantages over traditional workflows based on benchtop SPE, specifically: 1) reducing the volume of sample required for analysis and thereby easing activities associated with sample collection and storage, and 2) minimizing the time required for sample preparation before analysis. Through application to Swiss lake waters, we have also demonstrated the value of adding cyanopeptides beyond common microcystins when monitoring surface waters for cyanobacteria. The methods can be extended to other cyanobacterial metabolites that are compatible with the SPE and LCMS settings presented. We expect that the method is compatible to compounds of similar structural class, including additional microcystins, anabaenopeptins, cyanopeptolins, and aerucyclamides. Depending on the physiochemistry of other metabolites, the SPE sorbent material and elution workflow, LC column and eluent selection can be adopted as needed.

Based on method validation experiments, we set forth a series of recommendations for quantitative monitoring of cyanopeptides in surface water by online-SPE HPLC-HRMS/MS. Firstly, since isotopically-labeled standards are not available for most cyanopeptides, matrix-matched calibrants should ideally be used for analyte quantitation and injected periodically over the course of multiday analysis sequences. Secondly, 'blank- 
ing' nanopure water samples should be injected after each set of sample replicates or calibrants, to reduce quantification errors linked to carryover effects. Thirdly, due to the potential for compound instability in lake matrices, pooled quality control samples should be analysed periodically throughout an analysis sequence to monitor and potentially correct for such effects, including for compounds for which standards are not available.

Key challenges relating to the comprehensive assessment of cyanobacterial metabolites remains their large structural diversity, a lack of reference standards and isotopically labeled standards for most compounds, and thus the need for advanced analytical instrumentation to enable their accurate identification and quantification, before further testing becomes feasible. Not only are most compounds not available as standards, few reference mass spectra are available in open access libraries that can be used to enhance confidence in mass spectrometry-based metabolite identification. While more than 14000 reference mass spectra exist for micropollutants (e.g. European MassBank), ${ }^{[28]}<1 \%$ of known cyanopeptides have associated, publicly-available MS/MS data (e.g. The Global Natural Product Social Molecular Networking platform, https://gnps.ucsd.edu). We argue, therefore, that focus should now be applied to systematically recording MS/MS reference data for diverse cyanopeptides, ideally across multiple laboratories and using diverse MS instrumentation and detection conditions, with the resulting data shared via open-access portals to support cyanopeptide dereplication in the future.

\section{Acknowledgement}

We thank Professor Karl Gademann for providing a purified aliquot of aerucyclamide A, Francesco Pomati, Marta Reyes, Thea Bulas for lake sampling, and Eawag for funding.

\section{Received: October 31, 2021}

[1] a) E. M. L. Janssen, Water Res. 2019, 151, 488, https://doi.org/10.1016/j.watres.2018.12.048; b) R. Agha, A. Quesada, Toxins 2014, 6, 1929, https://doi.org/10.3390/toxins6061929.

[2] a) W. W. Carmichael, Hum. Ecol. Risk Assess. 2001, 7, 1393, https://doi.org/10.1080/20018091095087; b) S. Merel, D. Walker, R. Chicana, S. Snyder, E. Baures, O. Thomas, Environ. Int. 2013, 59, 303, https://doi.org/10.1016/j.envint.2013.06.013; c) S. Pouria, A. de Andrade, J. Barbosa, R. L. Cavalcanti, V. T. S. Barreto, C. J. Ward, W. Preiser, G. K. Poon, G. H. Neild, G. A. Codd, Lancet 1998, 352, 21, https://doi.org/10.1016/S0140-6736(97)12285-1; d) H. Matsunaga, K. I. Harada, M. Senma, Y. Ito, N. Yasuda, S. Ushida, Y. Kimura, Nat. Toxins 1999, 7, 81, https://doi.org/10.1002/(Sici) 1522-7189(199903/04)7:2<81::AidNt44>3.0.Co;2-O; e) J. Chen, P. Xie, L. Li, J. Xu, Toxicol. Sci. 2009, 108, 81, https://doi.org/10.1093/toxsci/kfp009.

[3] a) J. Huisman, G. A. Codd, H. W. Paerl, B. W. Ibelings, J. M. H. Verspagen, P. M. Visser, Nat. Rev. Microbiol. 2018, 16, 471 , https://doi.org/10.1038/s41579-018-0040-1; b) R. Cavicchioli, W. J. Ripple, K. N. Timmis, F. Azam, L. R. Bakken, M. Baylis, M. J. Behrenfeld, A. Boetius, P. W. Boyd, A. T. Classen, T. W. Crowther, R. Danovaro, C. M. Foreman, J. Huisman, D. A. Hutchins, J. K. Jansson, D. M. Karl, B. Koskella, D. B. M. Welch, J. B. H. Martiny, M. A. Moran, V. J. Orphan, D. S. Reay, J. V. Remais, V. I. Rich, B. K. Singh, L. Y. Stein, F. J. Stewart, M. B. Sullivan, M. J. H. van Oppen, S. C. Weaver, E. A. Webb, N. S. Webster, Nat. Rev. Microbiol. 2019, 17, 569, https://doi.org/10.1038/s41579-019-0222-5; c) H. W. Paerl, J. Huisman, Science 2008, 320, 57, https://doi.org/10.1126/science.1155398; d) H. E. Plaas, H. W. Paerl, Environ. Sci. Technol. 2021, 55, 44, https://doi.org/10.1021/acs.est.0c06653.

[4] a) S. Gkelis, T. Lanaras, K. Sivonen, Mar. Drugs 2015, 13, 6319, https://doi.org/10.3390/md13106319; b) H. Mazur-Marzec, M. J. Kaczkowska, A. Blaszczyk, R. Akcaalan, L. Spoof, J. Meriluoto, Mar. Drugs 2013, 11, 1, https://doi.org/10.3390/md11010001; c) V. R. Lopes, V. Ramos, A. Martins, M. Sousa, M. Welker, A. Antunes, V. M. Vasconcelos, Mar. Environ. Res. 2012, 73, 7, https://doi.org/10.1016/j.marenvres.2011.10.005;d)R.Kurmayer,E.Schober, L. Tonk, P. M. Visser, G. Christiansen, FEMS Microbiol. Lett. 2011, 317, 127, https://doi.org/10.1111/j.1574-6968.2011.02222.x;

H. I. Baumann, F. Juttner, Limnologica 2008, 38, 350 https://doi.org/10.1016/j.limno.2008.05.010.
[5] a) P. Ferranti, S. Fabbrocino, E. Chiaravalle, M. Bruno, A. Basile, L. Serpe, P. Gallo, Food Res. Int. 2013, 54, 1321, https://doi.org/10.1016/j.foodres.2012.12.028; b) M. Grabowska, J. Kobos, A. Torunska-Sitarz, H. Mazur-Marzec, Arch. Microbiol. 2014, 196, 697, https://doi.org/10.1007/s00203-014-1008-9; c) M. Welker, B. Marsalek, L. Sejnohova, H. Von Doehren, Peptides 2006, 27, 2090, https://doi.org/10.1016/j.peptides.2006.03.014; d) D. Jancula, L. Strakova, J. Sadilek, B. Marsalek, P. Babica, Environ. Sci. Pollut. Res. 2014, 21, 8006, https://doi.org/10.1007/s11356-014-2699-9.

[6] a) M. E. Monchamp, P. Spaak, I. Domaizon, N. Dubois, D. Bouffard, F. Pomati, Nat. Ecol. Evol. 2018, 2, 317, https://doi.org/10.1038/s41559-017-0407-0; b) M. E. Monchamp, J. C. Walser, F. Pomati, P. Spaak, Appl. Environ. Microb. 2016, 82, 6472, https://doi.org/10.1128/Aem.02174-16; c) T. Posch, O. Koster, M. M. Salcher, J. Pernthaler, Nat. Clim. Change 2012, 2, 809, https://doi.org/10.1038/Nclimate1581.

[7] WHO, 'Toxic cyanobacteria in water - A guide to their public health consequences, monitoring and management', Vol. 2, World Health Organization, Geneva, 2021

[8] M. R. Jones, E. Pinto, M. Torres, F. Dörr, H. Mazur-Marzec, K. Szubert, L. Tartaglione, C. Dell'Aversano, D. G. Beach, P. McCarron, C. O. Miles, K. Sivonen, D. P. Fewer, J. Jokela, E. M.-L. Janssen, Water Res. 2021, 196, 117017, https://doi.org/10.1016/j.watres.2021.117017.

[9] a) S. Bogialli, C. Bortolini, I. M. Di Gangi, F. N. Di Gregorio, L. Lucentini, G. Favaro, P. Pastore, Talanta 2017, 170, 322, https://doi.org/10.1016/j.talanta.2017.04.033; $\quad$ b) $\quad$ C. Flores, J. Caixach, J. Chromatography A 2015, 1407, 76, https://doi.org/10.1016/j.chroma.2015.06.022; $\quad$ c) $\quad$ M. L. Saker, J. Fastner, E. Dittmann, G. Christiansen, V. M. Vasconcelos, J. Appl. Microbiol. 2005, 99, 749, https://doi.org/10.1111/j.1365-2672.2005.02687.x; d) L. J. Beversdorf, C. A. Weirich, S. L. Bartlett, T. R. Miller, Toxins 2017, 9, 62, https://doi.org/10.3390/toxins9020062; e) M. Welker, M. Brunke, K. Preussel, I. Lippert, H. von Döhren, Microbiol.-Sgm. 2004, 150, 1785, https://doi.org/10.1099/mic.0.26947-0.

[10] a) D. I. Sharif, J. Gallon, C. J. Smith, E. Dudley, ISME J. 2008, 2, 1171, https://doi.org/10.1038/ismej.2008.68; b) A. Pereira Daniel, A. Giani, FEMS Microbiol. Ecol. 2014, 88, 175; c) A. L. Demain, A. Fang, in 'History of Modern Biotechnology I', Ed. A. Fichter, Springer, Berlin, Germany, 2001, p. 1 , https://doi.org/10.1007/3-540-44964-7.

[11] a) A. Rantala, D. P. Fewer, M. Hisbergues, L. Rouhiainen, J. Vaitomaa, T. Borner, K. Sivonen, Proc. Natl. Acad. Sci. USA 2004, 101, 568, https://doi.org/10.1073/pnas.0304489101; b) L. Rouhiainen, T. Vakkilainen, B. L. Siemer, W. Buikema, R. Haselkorn, K. Sivonen, Appl. Environ. Microb. 2004, 70, 686, https://doi.org/10.1128/Aem.70.2.686-692.2004; c) G. Christiansen, J. Fastner, M. Erhard, T. Borner, E. Dittmann, J. Bacteriol. 2003, 185, 564, https://doi.org/10.1128/Jb.185.2.564-572.2003; d) A. Zikova, A. Trubiroha, C. Wiegand, S. Wuertz, B. Rennert, S. Pflugmacher, R. Kopp, J. Mares, W. Kloas, Environ. Toxicol. Chem. 2010, 29, 561, https://doi.org/10.1002/etc.76; e) S. Kosol, J. Schmidt, R. Kurmayer, Eur. J. Phycology 2009, 44, 49, https://doi.org/10.1080/09670260802158659; f) R. Kurmayer, G. Christiansen, Freshwater Rev. 2009, 2, 31, https://doi.org/10.1608/FRJ-2.1.2.

[12] a) B. A. Neilan, L. A. Pearson, J. Muenchhoff, M. C. Moffitt, E. Dittmann, Environ. Microbiol. 2013, 15, 1239, https://doi.org/10.1111/j.1462-2920.2012.02729.x; b) T. K. Shishido, J. Jokela, D. P. Fewer, M. Wahlsten, M. F. Fiore, K. Sivonen, ACS Chem. Biol. 2017, 12, 2746, https://doi.org/10.1021/acschembio.7b00570.

[13] a) M. Lifshits, S. Carmeli, J. Nat. Prod. 2012, 75, 209, https://doi.org/10.1021/np200909x; b) T. Rohrlack, R. Skulberg, O. M. Skulberg, J. Phycology 2009, 45, 1259, https://doi.org/10.1111/j.1529-8817.2009.00757.x.

[14] a) S. Le Manach, N. Khenfech, H. Huet, Q. Qiao, C. Duval, A. Marie, G. Bolbach, G. Clodic, C. Djediat, C. Bernard, M. Edery, B. Marie, Environ. Sci. Technol. 2016, 50, 8324, https://doi.org/10.1021/acs.est.6b01903; b) M. Smutna, P. Babica, S. Jarque, K. Hilscherova, B. Marsalek, M. Haeba, L. Blaha, Toxicon 2014, 79, 11, https://doi.org/10.1016/j.toxicon.2013.12.009; c) I. Teneva, D. Asparuhova, B. Dzhambazov, R. Mladenov, K. Schirmer, Environ. Toxicol. 2003, 18, 9, https://doi. org/10.1002/tox.10096; d) I. Teneva, B. Dzhambazov, L. Koleva, R. Mladenov, K. Schirmer, Toxicon 2005, 45, 711, https://doi.org/10.1016/j. toxicon.2005.01.018; e) C. Keil, A. Forchert, J. Fastner, U. Szewzyk, W. Rotard, I. Chorus, R. Kratke, Water Res. 2002, 36, 2133, https://doi. org/10.1016/s0043-1354(01)00417-1.

[15] G. E. Chlipala, S. Mo, J. Orjala, Curr. Drug Targets 2011, 12, 1654, https://doi.org/10.2174/138945011798109455.

[16] a) I. Chorus, K. Sivonen, G. A. Codd, T. Börner, H. Von Doehren, M. Welker, E. Dittmann, Y. Claussner, K. Christopffersen, E. Schober, H. Utkilen, T. Rohrlack, S. Lyck, P. M. Visser, L. Tonk, D. R. Dietrich, S. J. Hoeger, N. Tandeau de Marsac, I. Iteman, V. Niesel, J. Fastner, T. 
Grummt, R. Heinze, A.-H. Ferreira, T. Warming-Svendsen, I. Flieger, G. Wessel, L. Rouhiainen, L. F. Morrison, 'Toxic and Bioactive Peptides in Cyanobacteria - PEPCY Report. https://www.uibk.ac.at/limno/files/pdf/final-report-pepcy.pdf', E. U., 2006; b) D. Filatova, M. R. Jones, J. Haley, O. Núñez, M. Farré, E. M.-L. Janssen, Environ. Sci. Eur. 2021, 33, 29, https://doi.org/10.1186/s12302-021-00472-4 ; c) L. J. Beversdorf, K. Rude, C. A. Weirich, S. L. Bartlett, M. Seeman, C. Kozik, P. Biese, T. Gosz, M. Suha, C. Stempa, C. Shaw, C. Hedman, J. Piatt, T. R. Miller, Water Res. 2018, 140, 280, https://doi.org/ 10.1016/j.watres.2018.04.032.

[17] a) S. Huntscha, H. P. Singer, C. S. McArdell, C. E. Frank, J. Hollender, J. Chromatography A 2012, 1268, 74, https://doi.org/10.1016/j.chroma.2012.10.032; b) H. Singer, S. Jaus, I. Hanke, A. Luck, J. Hollender, A. C. Alder, Environ. Pollut. 2010, 158, 3054, https://doi.org/10.1016/j.envpol.2010.06.013; c) K. Stoob, H. P. Singer, C. W. Goetz, M. Ruff, S. R. Mueller, J. Chromatography A 2005, 1097, 138, https://doi.org/10.1016/j.chroma.2005.08.030.

[18] a) A. Roy-Lachapelle, M. Solliec, S. Sauve, C. Gagnon, Talanta 2021, 223, https://doi.org/10.1016/j.talanta.2020.121802; b) A. Roy-Lachapelle, S. V. Duy, G. Munoz, Q. T. Dinh, E. Bahl, D. F. Simon, S. Sauve, Anal. Meth. 2019, 11, 5289, https://doi.org/10.1039/c9ay01132c; c) G. Munoz, V. D. Sung, A. Roy-Lachapelle, B. Husk, S. Sauve, J. Chromatography A 2017, 1516, 9, https://doi.org/10.1016/j.chroma.2017.07.096.

[19] M. R. Jones, E. Pinto, M. A. Torres, F. Dörr, H. Mazur-Marzec, K. Szubert, L. Tartaglione, C. Dell'Aversano, C. O. Miles, D. G. Beach, P. McCarron, K. Sivonen, D. P. Fewer, J. Jokela, E. M. L. Janssen, bioRxiv 2020 , 2020.04.16.038703, https://doi.org/10.1101/2020.04.16.038703.

[20] a) S. K. Zervou, C. Christophoridis, T. Kaloudis, T. M. Triantis, A. Hiskia, J. Hazard. Mater. 2017, 323, 56, https://doi.org/10.1016/j.jhazmat.2016.07.020; b) D. Filatova, O. Nunez, M. Farre, Toxins 2020, 12, https://doi.org/10.3390/toxins 12040247.

[21] 'European Medicines Agency: Validation of Analytical Procedures: Text and Methodology', Vol. CPMP/ICH/381/95, 1995

[22] a) B. Schulze, Y. Jeon, S. Kaserzon, A. L. Heffernan, P. Dewapriya, J. O'Brien, M. J. G. Ramos, S. G. Gorji, J. F. Mueller, K. V. Thomas, S. Samanipour, Trac-Trend Anal. Chem. 2020, 133, https://doi.org/10.1016/j.trac.2020.116063; b) W. B. Dunn, D. Broadhurst, P. Begley, E. Zelena, S. Francis-McIntyre, N. Anderson, M. Brown, J. D. Knowles, A. Halsall, J. N. Haselden, A. W. Nicholls, I. D. Wilson, D. B. Kell, R. Goodacre, The Human Serum Metabolome (HUSERMET) Consortium, Nat. Protoc. 2011, 6, 1060, https://doi.org/10.1038/nprot.2011.335.

[23] R. Natumi, E. M. L. Janssen, Environ. Sci. Technol. 2020, 54, 6063, https://doi.org/10.1021/acs.est.9b07334.

[24] P. B. Fayad, A. Roy-Lachapelle, S. V. Duy, M. Prevost, S. Sauve, Toxicon 2015, 108, 167, https://doi.org/10.1016/j.toxicon.2015.10.010.

[25] M. Skafi, S. V. Duy, G. Munoz, Q. T. Dinh, D. F. Simon, P. Juneau, S. Sauve, Toxicon 2021, 194, 44, https://doi.org/10.1016/j.toxicon.2021.02.004.

[26] M. E. Monchamp, I. Enache, P. Turko, F. Pomati, G. Risnoveanu, P. Spaak, Hydrobiologia 2017, 800, 155, https://doi.org/10.1007/s10750-017-3247-7.

[27] a) J. Fastner, M. Erhard, W. W. Carmichael, F. Sun, K. L. Rinehart, H. Ronicke, I. Chorus, Arch. Hydrobiol. 1999, 145, 147; b) L. Cerasino, S. Shams, A. Boscaini, N. Salmaso, Chem. Ecol. 2016, 32, 492, https://doi.org/10.1080/02757540.2016.1157175; c) J. F. Briand, S. Jacquet, C. Flinois, C. Avois-Jacquet, C. Maisonnette, B. Leberre, J. F. Humbert, Microb. Ecol. 2005, 50, 418, https://doi.org/10.1007/s00248-005-0186-z; d) T. Rohrlack, B. Edvardsen, R. Skulberg, C. B. Halstvedt, H. C. Utkilen, R. Ptacnik, O. M. Skulberg, Limnol. Oceanography 2008, 53, 1279 , https://doi.org/10.4319/1o.2008.53.4.1279.

[28] E. L. Schymanski, J. Jeon, R. Gulde, K. Fenner, M. Ruff, H. P. Singer, J. Hollender, Environ. Sci. Technol. 2014, 48, 2097, https://doi.org/10.1021/es5002105.

License and Terms

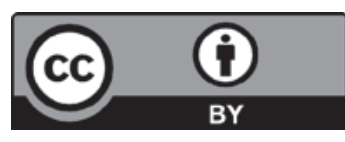

This is an Open Access article under the terms of the Creative Commons Attribution License CC BY 4.0. The material may not be used for commercial purposes.

The license is subject to the CHIMIA terms and conditions: (https://chimia.ch/chimia/about).

The definitive version of this article is the electronic one that can be found at https://doi.org/10.2533/chimia.2022.133 